\title{
La administración de los derechos de autor y derechos conexos por las sociedades de gestión en Nicaragua ${ }^{2}$
}

\author{
María Mercedes Martínez Guevara \\ Labora en el Poder Judicial \\ mariamercedes_mg@yahoo.com
}

\begin{abstract}
Resumen
Este trabajo aborda el tema de la formación y funcionamiento de las sociedades de gestión colectiva de derechos de autor y derechos conexos, a partir de la necesidad de los autores de velar por el respeto y protección de sus derechos patrimoniales como autores de obras artísticas o, como intérpretes o ejecutantes de las mismas, según sea el caso. Se plantea la forma de organización de estas sociedades, sus características y el papel que juega el Estado para garantizar el cumplimiento de los objetivos de las mismas, así como la capacidad que les otorga el ordenamiento jurídico para hacer efectivo el ejercicio de las acciones pertinentes, a fin de obtener la recaudación de las ganancias obtenidas por los usuarios derivados de la utilización de los bienes pertenecientes a los autores. Nuestra legislación asume en la Ley número 312, Ley de Derecho de Autor y Derechos Conexos, y en su Reglamento, la figura de la sociedad de gestión, regula su funcionamiento y le otorga facultades para ejercer los derechos de los autores, bajo la tutela del Estado; sin embargo, la actividad de estas entidades ha tenido dificultades en nuestra nación y en otros países, por el rechazo manifiesto de la sociedad bajo el argumento de que se pretende coartar el derecho individual al uso y disfrute de las creaciones artísticas y culturales.
\end{abstract}

Palabras clave: derechos de autor y derechos conexos/ sociedades de gestión colectiva/ derechos patrimoniales/ personas jurídicas

\begin{abstract}
This work addresses the issue of formation and functioning of collective management of copyright and related rights of the authors ensure respect and protection of their economic rights as authors of works of art or as performers, as the case may need societies. The form of organization of these societies, their characteristics and role of the State to ensure compliance with the objectives thereof, as well as the ability that gives them the legal system to ensure the exercise of the relevant actions for profit by users arising from the use of property belonging to the authors collection arises. Our legislation assumes the number 312, law law of copyright and related rights, and its regulations, the figure of the management company, regulates their operation and gives powers to exercise the rights of authors, under the tutelage of the State; however, the activity of these entities has had difficulties in our nation and in other countries, by the apparent rejection of society under the argument that it is seeking to stifle the individual's right to the use and enjoyment of cultural and artistic creations.
\end{abstract}

Key words: copyright and related rights/ collecting societies/ economic rights/ legal persons

2 El presente artículo es el resultado del trabajo de investigación realizado para obtener el título de Máster en Derecho de Empresas con especialidad en Asesoría Jurídica de Empresas; el cual además de ser evaluado por un Tribunal integrado por tres académicos; posteriormente, fue arbitrado por una Comisión a efectos de seleccionar a los participantes del II Encuentro de Investigación de Postgrado de la Universidad Centroamericana, Agosto 2010. 


\section{Introducción}

Al presentar este trabajo, nos proponemos dar a conocer la manera cómo se organizan las sociedades de gestión colectiva de derechos de autor, las que se plantean como objetivo principal, velar por el cumplimiento de la protección que han otorgado los Estados a esos derechos. Se muestra la existencia de estas entidades desde hace más de cien años, y el avance y desarrollo que han tenido por la contribución de organismos internacionales de Naciones Unidas y mediante la suscripción de convenios y tratados internacionales, hasta lograr homogeneizar criterios legales en normativas tipo para los distintos continentes del mundo, según sus características propias.

En nuestro país esta figura jurídica aparece contemplada en la novedosa y moderna Ley de Derecho de Autor y Derechos Conexos, que entró en vigencia en el año 2000; sin embargo, su organización, funcionamiento y actividades principales, son de insuficiente conocimiento por la sociedad, no solo en el campo de los creadores de obras artísticas e intérpretes, sino también de los usuarios en general; encontrando por ello resistencia en el cumplimiento de ciertas obligaciones que la legislación señala y cierto recelo de los artistas en depositar su confianza en esta entidad para que se encargue de recaudar los fondos producidos por la utilización de sus obras y proceda después al reparto de las ganancias, de acuerdo con la normativa establecida y aprobada por la entidad estatal correspondiente.

Se pretende con esta exposición, abrir una oportunidad para el debate sobre el tema, despertar el interés por mostrar las ventajas que ofrecen estas entidades, conocer sus desaciertos, los riesgos que se corren y la necesidad de fortalecer el interés por la creación de obras artísticas, con la seguridad de que los beneficios obtenidos con su uso llegará a sus creadores y de alguna manera servirá para fomentar y acrecentar el acervo cultural del país.

\section{Derechos de autor y derechos conexos, concepto}

El derecho de autor es reconocido como uno de los derechos básicos de la persona, en la Declaración Universal de los Derechos Humanos adoptada en 1948 por la Asamblea General de las Naciones Unidas en el artículo 27 dice: 
1. Toda persona tiene derecho a tomar parte libremente en la vida cultural de la comunidad, a gozar de las artes y a participar en el progreso científico y en los beneficios que de él resulten.

2. Toda persona tiene derecho a la protección de los intereses morales y materiales que le correspondan por razón de las producciones científicas, literarias o artísticas de que sea autora.

Tomando como referencia el artículo 2 del Convenio de Estocolmo que establece la Organización Mundial de la Propiedad Intelectual (OMPI), quedan bajo la denominación de propiedad intelectual los derechos relativos a: 1) las obras literarias, las interpretaciones de los artistas intérpretes y las ejecuciones de los ejecutantes, los fonogramas y las emisiones de radiodifusión, 3) las invenciones en todos los campos de la actividad humana, 4) los descubrimientos científicos, 5) los dibujos y modelos industriales, 6) las marcas de fábrica, de comercio y de servicio, así como a los nombres y denominaciones comerciales, 7) la protección contra la competencia desleal, 8) todos los demás derechos relativos a la actividad intelectual en los terrenos industrial, científico, literario y artístico (Antequera Parilli, Tomo I, 1998).

El objeto de los derechos intelectuales, es la producción intelectual, del espíritu y el talento humano. Estos derechos en sus diferentes facetas, tienen en común que conceden a su titular la facultad exclusiva de materializar la concepción protegida, y esa posición monopolística se origina como consecuencia de que el ordenamiento jurídico atribuya al creador la titularidad de un derecho subjetivo (Antequera Parilli, Tomo I, 1998).

Se entiende por Derecho de autor, en su sentido subjetivo, al conjunto de facultades del que goza un autor en relación con la obra que tiene originalidad o individualidad suficiente y que se encuentra comprendida en el ámbito de protección dispensada. En su sentido objetivo, se refiere a la denominación que recibe la materia que trata estos asuntos (Lipszyc, 1993).

Nuestra Constitución Política de la República, en el artículo 125 señala ...El Estado promueve y protege la libre creación, investigación y difusión de las ciencias, la tecnología, las artes y las letras, y garantiza y protege la propiedad intelectual (Constitución Política, 1987). 
Posteriormente, en el año 1999, se promulgó la Ley No. 312, Ley de Derecho de Autor y Derechos Conexos, que de manera general define en su artículo 1 el derecho de autor, como el conjunto de facultades legalmente reconocidas a los titulares de obras literarias, artísticas o científicas, y en el artículo 2 define al Autor como la persona natural que crea alguna obra, sea literaria, artística o científica ${ }^{3}$. La Ley de Propiedad Intelectual de España en su artículo 5 inciso 2, da una definición idéntica (Ley de Propiedad Intelectual, 1996).

Todas las leyes de derecho de autor tienen un principio o fundamento general. Dicho principio podría ser enunciado como que todo autor tiene derecho a obtener retribución económica por el producto de su mente.

$\mathrm{Al}$ crearse una obra surge, además de la relación causa-efecto, una relación de propiedad y pertenencia sobre el objeto creado. Tal relación de propiedad y pertenencia capacita al poseedor para usar y disponer de tal objeto conforme a sus propios intereses, sin excluir, de ninguna manera, los intereses económicos. Este es un principio inquebrantable y fundamental de las legislaciones autorales.

Los derechos pecuniarios o patrimoniales se refieren a la explotación económica de manera exclusiva de una obra o autorizar a otros su explotación, siendo el autor el titular originario del derecho patrimonial y sus herederos o causahabientes los titulares derivados.

Los titulares de los derechos patrimoniales podrán autorizar o prohibir la reproducción, publicación, edición o fijación material de una obra efectuada por cualquier medio, la comunicación, exhibición y transmisión pública, la distribución de la obra y cualquier utilización pública. El ejercicio de los derechos patrimoniales tiene una limitación de tiempo que marca la Ley (Vargas Fernández).

El Convenio de Berna para la Protección de las Obras Literarias y Artísticas, tratado internacional en materia de derecho de autor, enmarca este ámbito de protección cuando considera como obras protegidas:

...todas las producciones en el campo literario, científico y artístico, cualquiera que sea el modo o forma de expresión, tales como los libros, folletos y otros escritos; las conferencias, alocuciones, sermones y otras obras de la misma naturaleza; las obras dramáticas o dramático-musicales; las obras coreográficas

3 Ley No. 312, Ley de Derecho de Autor y Derechos Conexos, 26 de agosto de 1999. Publicado en La Gaceta, Diario Oficial No. 166 y 167 de 31 de agosto y 1 de septiembre de 1999. 
y las pantomimas; las composiciones musicales con o sin letra; las obras cinematográficas, a las cuales se asimilan las obras expresadas por procedimiento análogo a la cinematografía; las obras de dibujo, pintura, arquitectura, escultura, grabado, litografía; las obras fotográficas a las cuales se asimilan las expresadas por procedimiento análogo a la fotografía; las obras de artes aplicadas; las ilustraciones, mapas, planos, croquis y obras plásticas relativos a la geografía, a la topografía, a la arquitectura o a las ciencias. (9 de septiembre de 1886, y posteriores revisiones. Artículo 2. Publicación OMPI, No. 223(s), Ginebra, 1999).

Para el Derecho de autor es necesaria la expresión de las ideas de modo que sean perceptibles por los demás seres humanos, o sea, que solo es posible proteger la creatividad en los marcos del Derecho de autor cuando esta adquiere una expresión formal, sin que sea aplicable a las ideas, principios, métodos, procedimientos, cálculos matemáticos, etc. Es decir, que protege "la forma representativa, la exteriorización de su desarrollo en obras concretas aptas para ser reproducidas, representadas, ejecutadas, radiodifundidas, etc., según el género al cual pertenezcan y a regular su utilización” (Lipszyc, 1993).

La fórmula utilizada por el Convenio de Berna para describir las obras que protege el derecho de autor es enunciativa, al igual que la adoptada por muchas legislaciones. Esto ha servido para que sus disposiciones hayan sido aplicadas a nuevos tipos de obras y nuevos usos, producto de los cambios que se han producido en la tecnología y en los modos de expresión artística (Navarrete Alvarez, 2006).

\section{Naturaleza jurídica de los derechos de autor y derechos conexos}

Entre las principales teorías de la naturaleza jurídica de los derechos de autor, encontramos:

a) Teoría del derecho de propiedad

El reconocimiento en cabeza del autor de un derecho de propiedad sobre su obra, tuvo el propósito de satisfacer los justos anhelos de los creadores, dotándolos de un derecho fundamental, claro e inequívoco. Esta teoría ha sido posteriormente cuestionada, al establecer las diferencias entre el derecho de autor y el derecho de dominio sobre las cosas materiales (Lipszyc, 1993). 
b) Teoría del derecho sobre bienes inmateriales

Elaborada por Josef KOHLER, señala que el derecho del creador se trata de un derecho exclusivo sobre la obra considerada como un bien inmaterial, económicamente valioso y, en consecuencia, de naturaleza distinta del derecho de propiedad que se aplica a las cosas materiales. Según Kohler el derecho de autor tiene únicamente naturaleza patrimonial, tanto por su origen histórico como porque las normas principales de las leyes están dirigidas a la tutela de las facultades exclusivas de reproducción, representación, ejecución, recitación, etc., mediante las cuales su autor se asegura la obtención de un beneficio económico. Esta teoría fue criticada por crear una fractura sin razón, de la unidad y armonía del derecho de autor entre el momento de la creación de la obra y, aquel en cual al dar a conocer la obra, se manifiestan los derechos patrimoniales (Lipszyc, 1993).

c) Teoría de la personalidad

Sustentada originalmente en 1785 por el filósofo Emmanuel KANT, para quien el derecho de autor es en realidad un derecho de la personalidad. Para GIERKE, el objeto del derecho de autor es una obra intelectual que constituye una emanación de la personalidad de su autor, un reflejo de su espíritu que ha logrado individualizarla a través de su actividad creadora y solamente asume carácter patrimonial como elemento accesorio (Lipszyc, 1993).

\section{d) Teoría del derecho personal-patrimonial}

Los sostenedores de la tesis intermedia, consideraron que el derecho de autor tiene naturaleza particular, pues no obstante estar radicado en la persona, comprende facultades de carácter patrimonial. Por esta doble función de proteger intereses de la personalidad e intereses patrimoniales, no puede adscribirse exclusivamente a una de ambas categorías de derechos (Lipszyc, 1993).

e) Teoría de los derechos intelectuales

La doctrina de los derechos intelectuales fue inicialmente expuesta por el jurista belga PICARD, consideró incompleta la clasificación tripartita clásica de derechos personales, reales y de obligaciones, e introdujo el concepto de derechos intelectuales iura in re intellectuali, categoría de naturaleza sui generis y autónoma. Esta clasificación atiende al objeto del derecho -la obra - y se asemeja a la teoría de Kohler en el sentido de abrir 
una nueva categoría a fin de no asimilar bienes materiales y bienes inmateriales; en cambio Picard considera que los derechos intelectuales están integrados por dos elementos: el personal o moral del autor y el patrimonial o económico (Lipszyc, 1993).

\section{f) Teoría del derecho de colectividad}

Esta doctrina fue establecida por el jurista Galo de Boor en su estudio publicado en la revista Droit d'Auteur: "las obras del espíritu no son propiedad de los autores, por su destino, deben pertenecer al pueblo: si un ser humano, tocado por la gracia, hiciera actos de creador [...] este ser privilegiado no habrá podido jamás realizar su obra si no hubiera, por otra parte, logrado alimentarse en el inmenso tesoro representado por la cultura nacional".

También siguen estas teorías los jurisconsultos franceses Colin y Capitant: “¿No se podría decir que el verdadero propietario de las obras de arte y de los inventos es el público, a quien se beneficia?” (Vargas Fernández).

Aunque no es objeto directo de este trabajo, creemos adecuado afirmar que los derechos de autor participan de la naturaleza de ser derechos reales sobre bienes inmateriales, toda vez que como sostiene la doctrina se hallan caracterizados por ser reproducibles y por ser originados por la creatividad del autor.

\section{Elementos que comprende: sujetos y objeto}

Una manera de entender el valor del derecho de autor consiste en examinarlo desde la perspectiva del autor o creador. Se trata de personas de talento que tienen algo que decir mediante la expresión de sus ideas, la cual, protegida por el derecho de autor, contribuye de muchas maneras al bienestar de la sociedad (Koskinen-Olsson, Del artista al público. El derecho de autor y los derechos conexos y el sistema de gestión colectiva del derecho de autor al servicio de los creadores y consumidores).

$\mathrm{El}$ autor es la persona física que crea una obra sin embargo, existe una indebida aplicación del término "autor" para referirse al titular del derecho sobre la creación, sobre todo a partir de polémica en torno a la consideración de atribuir condición de autor a las personas jurídicas o personas colectivas como titulares originarios del derecho de autor (Antequera Parilli, Tomo I, 1998). 
La Ley No. $312^{4}$, Ley de Derecho de Autor y Derechos Conexos, define en el artículo 2: "Autor: es la persona natural que crea alguna obra, sea literaria, artística o científica”. Es el autor quien está protegido directamente por la ley, al señalarlo expresamente el art. 4 de la ley5.

Si bien el derecho de autor pertenece al creador y el derecho nace con la creación, el título originario sobre la obra debe corresponder a quien la ha creado, quien además conserva, a pesar de cualquier transmisión inter vivos, aquellas facultades de orden moral. Pero, no impide que las facultades que conforman el derecho patrimonial sean susceptible de trasferencia a un tercero, a título derivativo, de manera que la explotación de la obra puede ser ejercida por un derechohabiente del creador (Antequera Parilli, Tomo I, 1998).

Respecto de la creación fruto del talento de varios individuos, es decir, las obras realizadas en colaboración y las colectivas, la coautoría estará siempre reconocida a los que han contribuido con un aporte personal creativo, y no quienes participan en la ejecución o producción de la obra fruto del ingenio de otros. Es el caso de obras audiovisuales, obras científicas, las didácticas y musicales, donde compositor y escritor se ponen de acuerdo para realizar la obra común. Por el contrario, no son obras en colaboración aquellas que consisten en una simple yuxtaposición de trabajos individuales.

La obra originaria no ofrece inconveniente al momento de atribuir la condición de autor y la titularidad originaria de los derechos, pues éste pertenece a la persona física que realiza la creación original. Las obras derivadas y compuestas, son las que se basan en una preexistente, realizada sin la colaboración del autor originario, pero le subsisten siempre sus derechos morales y patrimoniales.

Por otra parte, la transformación supone una actividad creativa que merece protección, por lo que también ha sido universalmente acogido el principio que protege como obras sin perjuicio de los derechos del autor de la obra original, a las traducciones, adaptaciones, arreglos musicales y transformaciones de una obra literaria o artística. De manera que son protegidas en forma análoga a la original, sin embargo, no estarían facultados para autorizar una reelaboración de su obra derivada, ya que podría afectar la originalidad y los derechos de autor de la obra primigenia (Antequera Parilli, 1998).

4 Ley No. 312. Ley de Derecho de Autor y Derechos Conexos. Publicado en La Gaceta, Diario Oficial No. 166 y 167 de 31 de agosto y 1 de septiembre de 1999.

5 Ley No. 312, artículo 4: El Derecho de Autor de una obra literaria, artesanal, artística o científica corresponde al autor por el solo hecho de su creación. 
La Ley de Derecho de Autor, en su artículo 2.17 define la obra colectiva de la siguiente manera: Es la creada por varios autores por iniciativa y bajo la responsabilidad de una persona natural o jurídica que la edita y divulga bajo su nombre y en la que, o no es posible identificar a sus autores en razón de su número, o sus diferentes contribuciones se funden de tal modo en el conjunto, con vista al cual ha sido concebida, que no es posible atribuir a cada uno de ellos un derecho indiviso sobre el conjunto realizado.

Respecto a la titularidad del derecho de la obra colectiva, el artículo 8 de la Ley de Derecho de Autor, señala que corresponderá a la persona que la edite o divulgue, salvo pacto en contrario. En cuanto al ejercicio de sus derechos, señala el artículo 9 LDA, que una vez divulgada la misma, los coautores ejercerán sus derechos de común acuerdo, sin que ninguno de ellos pueda rehusar, injustificadamente, su consentimiento.

Las obras en colaboración, son las creadas conjuntamente por dos o más personas naturales, según el artículo 2.16 LDA; la protección de estas obras en nada difiere de las estudiadas para el supuesto de autores individuales (Bendaña Guerrero, 2006).

El objeto o bien jurídico protegido en el derecho de autor es la obra literaria, artística o científica. Para el Glosario de la Organización Mundial de la Propiedad Intelectual (OMPI), obra es "toda creación intelectual original expresada en una forma reproducible" (Antequera Parilli, 1998, p. 121), otra definición de obra es la señalada por el autor argentino Miguel Ángel EMERY: “Toda expresión personal de la inteligencia que tenga individualidad, que desarrolle y exprese, en forma integral, un conjunto de ideas y sentimientos que sean aptos de ser hechos públicos y reproducidos" (Bendaña Guerrero, 2006, p. 57).

Para el derecho de autor, obra es la expresión personal de la inteligencia que desarrolla un pensamiento que se manifiesta bajo una forma perceptible, tiene originalidad o individualidad suficiente, y es apta para ser difundida y reproducida (Lipszyc, 1993).

Para hablar de obra como objeto de derecho de autor, es preciso partir de las siguientes premisas:

- Que el objeto de la tutela debe ser el resultado del talento creativo del hombre, en el dominio literario, artístico o científico. Quedan 
excluidos los productos de un trabajo intelectual que no concluyen en un aporte creativo propio.

- Que esa protección es reconocida con independencia del género de la obra, su forma de expresión, mérito o destino. Siempre que implique una aportación creativa.

- Que ese producto del ingenio humano, por su forma de expresión, exige características de originalidad. Esta originalidad apunta a su individualidad, es decir que el producto creativo, por su forma de expresión, ha de tener suficientes características propias como para distinguirlo (Antequera Parilli, Tomo I, 1998).

3. Tipos de derechos que integra, sus facultades fundamentales y forma de transferirlos

El contenido de los derechos de autor abarca los llamados derechos morales y los patrimoniales y ambos son ejercidos sobre la obra como objeto de protección. Convenios internacionales y una gran parte de las legislaciones nacionales en esta materia, reconocen y protegen ambos derechos; sin embargo, los acuerdos comerciales que tratan los temas de propiedad intelectual, como el Acuerdo sobre los Aspectos de los Derechos de Propiedad Intelectual relacionados con el Comercio (ADPIC) ${ }^{6}$ que obliga a todos los miembros de la Organización Mundial de Comercio (OMC), no protegen los derechos morales - al igual que el sistema del copyright (Navarrete Alvarez, 2006, p. 26).

Las facultades que integran el derecho moral del autor son las siguientes:

- El derecho a decidir sobre la divulgación de su obra, conocido como derecho de publicación.

- El derecho a exigir el reconocimiento a su condición de creador de la obra, es decir, al reconocimiento de su paternidad.

- El derecho a la integridad o respeto a la obra, que equivale a protegerla de mutilaciones, modificaciones y utilizaciones.

- El derecho de retracto o arrepentimiento, da derecho al autor a retractarse y retirar la obra de circulación o comercio.

Los derechos patrimoniales se refieren al derecho exclusivo del autor de recibir beneficios económicos por todas las formas de utilización de la obra que sean factibles, revisten las particularidades siguientes: El

6 En 1995 entró en vigor el Acuerdo sobre los ADPIC, en inglés TRIPS, suscrito en 1994 entre la OMC y la OMPI, de obligatorio cumplimiento para todos los países miembros de la OMC. 
derecho patrimonial es exclusivo, es de contenido ilimitado, no está sometido al sistema numerus clausus, es disponible, es expropiable, es renunciable, es embargable, es temporal (Antequera Parilli, Tomo I, 1998).

El autor tiene el derecho de autorizar o prohibir, salvo excepciones previstas en las leyes, todas las utilizaciones, usos o formas de explotación de su obra y debe ser remunerado por todos estos conceptos. Para hacerlo posible se han creado diversos mecanismos entre los que se encuentran las sociedades de gestión colectiva, encargadas de la negociación de las condiciones en que sus obras -0 sus prestaciones artísticas o aportaciones industriales- serán utilizadas por los difusores y otros usuarios, el otorgamiento de las respectivas autorizaciones, el control de las utilizaciones, la recaudación de las remuneraciones devengadas y su distribución o reparto entre los beneficiarios (Navarrete Alvarez, 2006, p. 28).

Los derechos de autor son transferibles; pero su transmisión es distinta si se transfieren a título universal, por causa de muerte, o a título singular, por acto entre vivos. Los derechos de orden moral se transmiten en cuanto a su ejercicio y a veces con ciertas limitaciones, a los herederos $\mathrm{u}$ otros causahabientes. Tales facultades son inalienables por acto entre vivos.

Los derechos de carácter patrimonial son transmisibles total o parcialmente, a través de contratos o presunciones legales de cesión, objeto de licencias o autorizaciones de uso otorgadas a terceros, para la explotación de la obra (Antequera Parilli, Tomo I, 1998).

Se llama limitaciones al derecho de autor a las barreras que se imponen al derecho exclusivo del autor sobre su obra y tienen como fundamento el necesario equilibrio entre los intereses del autor que crea las obras y el de la sociedad que desea y necesita el disfrute de las mismas con el mínimo de restricciones. Entre ambos intereses, o sea, el del autor y el de la sociedad, se encuentra el del empresario o utilizador, ente necesario para la difusión de las obras.

Las limitaciones al derecho de autor están basadas en intereses de orden educativo, cultural e informativo y tienen como características comunes que: 
- Restringen el derecho exclusivo del titular sobre la explotación económica de la obra.

- Están motivadas por razones de política social, fundamentalmente, como garantizar el acceso a las obras para satisfacer el interés público.

- No afectan el derecho moral del autor, por tanto:

* Solo son aplicables una vez que el autor ha ejercido el derecho de divulgación.

* Se debe mencionar el nombre del autor y la fuente.

* No se puede modificar la obra.

La principal limitación al derecho de autor lo constituye el régimen del dominio público. Después de la muerte del autor y transcurrido un determinado tiempo -50 años según el Convenio de Berna, 70 años según ha fijado la Unión Europea- la obra puede ser utilizada por toda la sociedad sin necesidad del consentimiento de los herederos del autor y sin remuneración (Navarrete Álvarez, 2006).

Las limitaciones al derecho de autor son básicamente de dos tipos: las que autorizan la utilización libre y gratuita, y las que están sujetas a remuneración, son las que constituyen licencias no voluntarias.

En cuanto a las razones que motivan dichas limitaciones, generalmente se conceden con fines educativos, permitiendo el uso de la obra a título de ilustración en la enseñanza, la reproducción por bibliotecas y archivos, para la ejecución y representación de obras en escuelas, el derecho de cita, para uso de la información tales como reseñas de prensa y obras implicadas en acontecimientos públicos, en procesos legales y otros como grabaciones efímeras, sistema Braille, parodias, la representación o exhibición en lugares públicos, etc. Además, se prevé como una limitación al derecho de autor, la copia privada para uso personal (Lipszyc, 1993).

También las legislaciones prevén licencias no voluntarias que implican la utilización sin autorización pero con remuneración. Tal es el caso de la licencia para la reproducción mecánica - permite a los productores de fonogramas grabar obras ya fijadas con anterioridad-, licencias para la radiodifusión y distribución por cable y la que se otorga en beneficio de los países en desarrollo para reproducir y traducir obras, en determinadas condiciones y para uso escolar. Estas licencias tuvieron 
su fundamento en la imposibilidad del control de determinados usos, pero están llamadas a desaparecer en la medida en que las sociedades de gestión logren el control sobre los mismos. Las licencias obligatorias son otorgadas por las sociedades de gestión.

Muy relacionado con los derechos de autor se encuentra la protección de los llamados derechos conexos. Su protección es incluida por primera vez en un tratado internacional en la Convención de Roma de 1961 y su objetivo es proteger la actividad de otras personas o entidades que participan en la puesta a disposición del público de las obras y cuya participación no era protegida por el Derecho de autor. Agrupados bajo la denominación de derechos conexos, la Convención de Roma benefició a los artistas, intérpretes o ejecutantes, productores de fonogramas y organismos de radiodifusión?.

Los derechos conexos o derechos afines no protegen obras propiamente dichas, sino determinadas prestaciones de muy diverso contenido, tales como la interpretación o ejecución que permite que una obra musical sea conocida; la inversión y otras acciones técnicas, artísticas, comerciales y organizativas que realiza un productor de fonograma, a fin de conformar un disco que permita su difusión y circulación en el mercado; y la del organismo de radiodifusión que emite una señal, con programas y obras para su disfrute más allá de cualquier distancia.

La duración de la protección de los derechos conexos, de conformidad con la Convención de Roma, es de 20 años a partir del término del año en que se haya realizado la actuación, la fijación (grabación) o la emisión (Navarrete Alvarez, 2006).

En el caso de la legislación nicaragüense, las excepciones y limitaciones al derecho de autor se encuentran regulados a partir del artículo 31 de la Ley No. 312, y son las siguientes:

1. Copia privada (art. 31) una sola copia, para uso personal y sin ánimo de lucro no necesita de autorización alguna. La ley nacional señala, sin embargo, se enumeran una serie de casos donde no es aplicable la excepción.

7 Convención de Roma: Convención Internacional sobre protección de los artistas intérpretes y ejecutantes, productores de fonogramas y organismos de radiodifusión, Roma, 1961. 
2. Derecho de Cita (art. 32)

3. Reproducción de Obras para la Enseñanza (art. 33)

4. Reproducción de Obras mediante Sistema Braille u otro análogo (art. 34)

5. Reproducción de Obras para uso de Bibliotecas y Archivos (art. 35)

6. Anotación de Conferencias o Lecciones en Centros de Enseñanza (art. 36)

7. Parodias (art. 37)

8. Comunicación pública en establecimientos comerciales (art. 38)

9. Copia de Programas de Ordenador (art. 39)

10. Reproducción de artículos de actualidad (art. 40)

11. Reproducción de Conferencias, Discursos, Alocuciones, Informes ante los Tribunales o Autoridad Administrativa (art. 41)

12. Reproducción de Obras sobre acontecimientos de actualidad (art. 42)

13. Reproducción de obras artísticas ubicadas permanentemente en sitios públicos (art. 43).

El derecho de autor también se encuentra limitado desde el punto de vista temporal. Nuestra legislación establece un plazo de protección equivalente a la vida del autor y 70 años después de su fallecimiento (art. 27). En el caso de los derechos conexos, el artículo 90 señala que tienen una duración de setenta años, contados desde el primero de enero del año siguiente al de la primera publicación de la interpretación o ejecución, o en su defecto al de su creación. Cuando los plazos expiran se le denomina obra de domino público ${ }^{8}$.

\section{La persona jurídica}

\section{Concepto y naturaleza}

Se define como persona a cualquier entidad que de conformidad con el derecho positivo que lo regula, tiene derechos, facultades, obligaciones o responsabilidades jurídicas. El Derecho romano se planteó el problema de la persona jurídica como la cuestión del reconocimiento, o de la atribución de personalidad o capacidad jurídica a ciertas entidades, es decir del reconocimiento o atribución del carácter de personas jurídicas o a cosas o a individuos. La noción de capacidad se encuentra así,

8 Seminario "Funcionamiento y Organización de la primera sociedad de gestión colectiva de derechos de autor NICAUTOR" Managua, 4 de marzo de 2005. Ministerio de Fomento Industria y Comercio, OMPI y CISAC. 
inseparablemente vinculada con la noción de persona jurídica (Instituto de Investigaciones Jurídicas, 1998).

Del concepto de persona se sigue el de personalidad. El concepto de personalidad es propio de la dogmática moderna y funciona como sinónimo de capacidad jurídica. Así, en el discurso jurídico por "personalidad" se entiende "la capacidad de ser persona". Goza de personalidad o capacidad jurídica quien tiene derechos, facultades, obligaciones y responsabilidades jurídicas.

El derecho positivo otorga capacidad o personalidad jurídica a entidades que no son seres humanos. "Son personas jurídicas: $1^{\circ}$. Las corporaciones, asociaciones y fundaciones... reconocidas por la ley... $2^{\mathrm{o}}$. Las asociaciones... a las que la ley concede personalidad propia..." (art. $35 \mathrm{CC}$ español). "Son personas morales: I. "... los Estados, los municipios; II. Las demás corporaciones reconocidas por la ley...” (art. 25 CC español).

Algunos juristas sostienen que además de las personas físicas, existen otras entidades que son personas jurídicas. Afirman que las personas colectivas están configuradas por ciertos fenómenos que se dan efectivamente en la vida social; siendo independientes de la conducta de determinados hombres. La entidad que constituye una persona colectiva, es la voluntad social que se independiza de la de cada uno de los individuos participantes y funciona como un elemento autónomo. Según otros autores, las personas colectivas son instituciones orientadas hacia ciertos fines y alrededor de los cuales se reúnen un grupo de hombres interesados en su concretación (Instituto de Investigaciones Jurídicas, 1998).

En nuestra legislación, el Código Civil define qué es persona en su artículo 1: Es persona todo ser capaz de ejercer derechos y contraer obligaciones. Las personas son naturales y jurídicas. El artículo $3 \mathrm{C}$. señala: Llámanse personas jurídicas las asociaciones o corporaciones temporales o perpetuas, fundadas con algún fin o por algún motivo de utilidad pública, o de utilidad pública y particular conjuntamente, que en sus relaciones civiles representen una individualidad jurídica.

El artículo 76 del Código Civil señala que las asociaciones o corporaciones tienen entidad jurídica, si han sido creadas o autorizadas por la ley para 
ejercer todos los derechos civiles relativos a los intereses legítimos de su instituto; de no ser así, serían consideradas como simples asociaciones civiles o comerciales (Cuadra Zavala, 2004).

Por su parte, el Código de Comercio en su artículo 119 se refiere a la sociedad comercial que adquiere personalidad jurídica distinta a la de sus asociados, la que se forma por la reunión de un fondo común, suministrado por los accionistas sólo hasta el monto de sus respectivas acciones, y que será administrada por mandatarios revocables, y conocida por la designación del objeto de la empresa (art. 201 CC).

En relación a la regulación de las Personas Jurídicas civiles y religiosas sin fines de lucro, señala la Ley No. 147, que es la Asamblea Nacional la autoridad que otorga y cancela la personalidad jurídica de dichas asociaciones, debidamente publicadas en La Gaceta, Diario Oficial y además los estatutos de las mismas, deberán inscribirse en el registro correspondiente ${ }^{9}$.

Por otra parte, el artículo 4 de la misma ley, advierte sobre la naturaleza jurídica de estas personas, cual es servir con una finalidad de bien público y con una administración reglamentada.

Acerca del tema de la naturaleza de la persona jurídica, hay varias teorías formuladas sobre si éstas tienen o no realidad. Así encontramos:

- Según la teoría de la ficción la persona jurídica no es más que una creación legal. El ordenamiento jurídico conceptúa a la unión de personas o a los bienes destinados a un fin benéfico como si fuera un sujeto de derecho, una persona. Este criterio se remonta a la época medieval para evitar el castigo de las ciudades o corporaciones que se rebelaban en contra de la autoridad del emperador o del Papa, y así recayera sobre cada uno de los ciudadanos o miembros de la corporación, de allí que estas reuniones de personas no eran más que un mero nombre, una cosa incorporal, que no podía pecar, ni cometer delito (Diez-Picazo \& Gullón, 2002).

- Por su parte para Savigny, las únicas personas jurídicas son personas físicas. Sin embargo, el ordenamiento jurídico puede, teniendo en cuenta razones de utilidad, suponer ficticiamente la existencia

9 Ley No. 147, Ley General sobre Personas Jurídicas sin Fines de Lucro, publicada en La Gaceta, Diario Oficial No. 102 del 29 de mayo de 1992. 
de entidades que no son hombres, como soporte de derechos y obligaciones. Esas entidades no existen en la realidad, pero los juristas hacen como si existieran, atribuyéndoles una "voluntad" destinada al cumplimiento de ciertos fines jurídicos. Desde este enfoque, el derecho tiene absoluto arbitrio para crear o disolver personas jurídicas, toda vez que son meros artificios técnicos y su capacidad se limita al objeto de su creación por el derecho (DiezPicazo \& Gullón, 2002).

- La teoría orgánica expuesta por Gierke, defiende que la persona jurídica es de naturaleza "supraindividual", que se trata de una persona efectiva y completa, como la persona individual, su alma está en la voluntad común, su cuerpo en el organismo asociativo (De Castro y Bravo, 1984).

- Otros autores como Ferrara, sostienen que la personalidad es un producto del orden jurídico y surge por el reconocimiento del derecho objetivo. Señala que si bien el hombre como ente racional y capaz de voluntad, es persona por obra del Derecho, nada se opone a que la personalidad pueda ser concedida a otros entes que no sean hombres, sino formas de convivencia humana.

- En esa dirección, Coviello afirma que uno de los modos de proteger la actividad encaminada a intereses sociales, es la de tratar a los individuos unidos entre sí como si fuesen una sola persona. Es sin duda una abstracción, pero que se funda en la realidad, por cuanto es real la unidad de los intereses y fines que persiguen. La abstracción, dice, no es una ficción, se apoya en una invención, en un hecho contemplado de forma diversa a como es (Diez-Picazo \& Gullón, 2002).

\section{Elementos materiales y formales}

Podríamos sintetizar que la persona jurídica consta de los siguientes elementos materiales: pluralidad de personas, bienes y fin de la colectividad.

Pluralidad de personas, es el tenerse entre sí como socios varias personas unidas por un fin común. Al respecto, en el antiguo Derecho se planteó la cuestión de que si la reducción a un solo socio extinguía la sociedad, a lo que se respondió negativamente contando con la posible reconstitución de la pluralidad. 
Bienes, se refiere a la constitución del patrimonio fundacional y los recursos económicos previstos.

Acerca de la finalidad, el propósito común de la asociación lo constituye el vínculo que une a los asociados; estos fines deberán ser lícitos, es decir no contrarios a las leyes y las buenas costumbres; y determinados, es decir que se establezca claramente acerca de las actividades a desarrollar (De Castro y Bravo, 1984).

Los elementos formales tienen destacada importancia, dada su característica de incorporeidad física, se tiene por tales al Estatuto, que viene a constituir la estructura ósea de la persona jurídica, es el que la sostiene y la individualiza. La publicidad, requisito indispensable para su reconocimiento social, que posibilita la actuación normal en el tráfico jurídico de la persona jurídica. Estos elementos formales son garantía para que una organización sea considerada persona jurídica.

El estatuto, es fundamento de la existencia y desenvolvimiento de la persona jurídica; las leyes modernas han procurado detallar sus cláusulas, algunas de ellas imprescindibles como la fijación de su objeto o finalidad, la determinación de sus órganos o representantes, las condiciones para ser y dejar de ser socios o asociados. Estará en todo caso, sometido y limitado por las reglas imperativas o dispositivas del ordenamiento jurídico (De Castro y Bravo, 1984).

La publicidad es la prueba legal de la existencia de la persona jurídica por lo que se requiere su inscripción en el Registro, cuyos datos sirven a efectos de identidad y como título de legitimación para el ejercicio de facultades y derechos (De Castro y Bravo, 1984).

\section{Características}

La doctrina ha clasificado a las personasjurídicas según sus características en personas jurídicas perfectas e imperfectas.

Persona jurídica perfecta, se construye tomándola como pareja de la persona humana, con existencia y patrimonio propio y separado, desligadas de modo tajante de la vida de sus miembros y órganos. La capacidad jurídica y de obrar de las personas jurídicas, no tiene otros límites que los establecidos, por carecer de un cuerpo de la misma naturaleza que el humano (De Castro y Bravo, 1984). 
Son las sociedades anónimas, o las agrupaciones de personas tipo asociación, o en una organización tipo fundación, que constituyen unidades cerradas herméticamente, con propia e inviolable zona íntima; y, siempre como la persona física, con capacidad de sujeto de derechos y obligaciones, participando como tal en el tráfico jurídico por medio de sus órganos.

Persona jurídica imperfecta, serían así denominadas aquellas compañías colectivas y comanditarias, en las que los socios colectivos quedan obligados, personal y solidariamente, a las resultas de las operaciones de la compañía. De allí la diferencia con las sociedades civiles, en la cual los socios no quedan obligados solidariamente por ellas (De Castro y Bravo, 1984).

Como características comunes de las diversas personas jurídicas, se pueden señalar las siguientes:

1. Propia e independiente capacidad jurídica y de obrar. Pueden adquirir y poseer bienes de toda clase y ejercitar acciones civiles o criminales, conforme a las leyes o su constitución. Podrán comparecer en juicio como demandantes o demandadas, por medio de las personas que legalmente las representa.

2. A diferencia de la persona física, tiene una estructura artificial. Se requiere que tenga estatuto o especial reglamentación, en el que habrán de establecer quiénes son sus órganos o representantes. Se extinguen una vez realizado el fin por el cual se constituyeron.

3. Deben tener una finalidad u objeto lícito, según su clase o género.

4. Los bienes constituyen un patrimonio personal separado del patrimonio de sus miembros o representantes.

5. Publicidad, es decir que su existencia, nacimiento y extinción, debe constar en un modo público (De Castro y Bravo, 1984).

\section{La entidad de gestión colectiva}

\section{Referencia histórica}

Los documentos y crónicas de la historia nos muestran que las sociedades de gestión vieron por primera vez la luz en Francia, para permitir que los autores parisinos pudieran obtener una remuneración por sus obras representadas en las grandes ciudades de provincia (Asociación de Compositores y Autores Musicales). 
Su historia se inicia el 3 de julio de 1777 con la fundación del Bureau de Législation Dramatique, a instancias de Pierre-Augustin Caron de Beaumarchais, el célebre comediógrafo de El barbero de Sevilla y Las bodas de Fígaro. Acompañado por varios de los dramaturgos de moda de ese entonces, como Sedaine, Marmontel, Saurin y otros, luchó con admirable tenacidad por el reconocimiento de los derechos de los autores (Lipszyc, 1993).

En 1791 cuando la Asamblea Constituyente de la Revolución Francesa consagró el derecho de representación, primer derecho de autor reconocido, el Bureau se transformó en una Agencia General de recaudación de derechos. Un número considerable de autores dramáticos y líricos confiaron a Framery, primer Agente General de Autores Dramáticos, por medio de poder otorgado ante notario, la administración de sus obras.

Se dieron a conocer a los teatros de Francia las condiciones a las cuales los autores sujetaban el uso de sus obras, se consiguieron firmar los primeros contratos generales de representación con un cierto número de teatros. El sistema de percepción se organizó definitivamente en la Societé des Auteurs et Compositeurs Dramatiques (SACD), transformando así a la primera agrupación de creadores en una verdadera sociedad de autores.

Por otra parte, los autores literarios celebraron el 31 de diciembre de 1837, la primera asamblea general de la Société des Gens de Lettres (SGDL), la asociación profesional a la que quedaron unidos los nombres de grandes escritores franceses como Honoré de Balzac, Alexandre Dumas y Victor Hugo; tuvo como primer objetivo realizar una campaña contra los periódicos que reproducían las obras sin autorización, ni pago (Lipszyc, 1993).

Pero los hechos que condujeron a una administración colectiva plenamente desarrollada solo comenzaron en 1847, cuando el incidente en "Les Ambassadeurs", un “café concert” de la avenida Champs Élysées, en París, donde dos compositores - Paul Henrion y Víctor Parizot - y un escritor, Ernest Bourget, se negaron a pagar por sus asientos y comida, al verificar que nadie manifestaba intención de pagarles por las obras que ejecutaba la orquesta. Apoyado por su editor, entablaron demanda contra el establecimiento y ganaron el pleito, siendo el propietario de "Les Ambassadeurs" condenado a pagar una importante suma de dinero por regalías (Asociación de Compositores y Autores Musicales). 
Con este fallo judicial se abrieron nuevas posibilidades para los compositores y autores de obras musicales no dramáticas. Era evidente, sin embargo, que no les sería posible controlar y hacer valer individualmente los nuevos derechos que se les reconocían. La comprensión de este hecho dio origen en 1850 a la fundación de un organismo de recaudación, poco después fue sustituido por la Société des Auteurs, Compositeurs et Editeurs de Musique SACEM, la más antigua sociedad de gestión de derecho de autor musical, que hasta hoy continúa en actividad.

A fines del siglo XIX y durante los primeros decenios del siglo pasado se formaron en casi todos los países europeos organizaciones similares. Por ejemplo, en 1899 se fundó la Sociedad General de Autores y Editores de España (SGAE), que ya cumplió su primer centenario.

La cooperación nacida entre esas sociedades llevó a la necesidad de crear un organismo internacional que coordinara sus actividades y contribuyera a la promoción de la gestión colectiva en todo el mundo. En junio de 1926, los delegados de 18 sociedades fundaron la Confederación Internacional de Sociedades de Autores y Compositores, CISAC, con sede en París, que hoy cuenta con 200 sociedades miembros (Asociación de Compositores y Autores Musicales).

En América Latina, los inicios se remontan a 1910, con la Sociedad Argentina de Autores Dramáticos y Líricos, que luego de divisiones internas dio paso en 1934, a la Sociedad General de Autores dela Argentina (ARGENTORES), para la administración colectiva de los derechos de representación dramática, y en 1936, con la fusión de organizaciones disidentes, la Sociedad Argentina de Autores y Compositores de Música (SADAIC).

Posteriormente, surgieron entidades autorales, algunos como sociedades de derechos generales y en ocasiones para la gestión de algunos modos de explotación, en países como Bolivia, Brasil, Colombia, Chile, Costa Rica, Cuba, Ecuador, Guatemala, México, Panamá, Paraguay, Perú, Uruguay y Venezuela (Antequera Parilli, Tomo II, 1998).

\section{Concepto}

Las entidades de gestión colectiva de derechos de propiedad intelectual, pueden definirse como organizaciones privadas de base asociativa y naturaleza no lucrativa que se dedican en nombre propio o ajeno a la 
gestión de derechos de propiedad intelectual de carácter patrimonial por cuenta de sus legítimos titulares (texto refundido de la Ley de Propiedad Intelectual, 1996).

El artículo 10 de la Ley 44 de 1993 de Colombia establece: "Los titulares de derechos de autor y derechos conexos podrán formar sociedades de gestión colectiva y de derechos de autor y derechos conexos sin ánimo de lucro con personería jurídica para la defensa de sus intereses conforme a las disposiciones establecidas en la Ley 23 de 1982 y en la presente ley".

Agrega en sus artículos 11 y 12 que el reconocimiento de la personería jurídica a las sociedades de gestión colectiva de derechos de autor y derechos conexos será conferido por la Dirección Nacional del Derecho de Autor, mediante resolución motivada. No podrán funcionar con menos de cien (100) socios, quienes deberán pertenecer a la misma actividad y estas sociedades estarán siempre obligadas a aceptar la administración de los derechos de sus asociados (Ley de Derecho de Autor, 1993).

Se entiende por gestión colectiva el sistema de administración de derechos de autor y de derechos conexos por el cual sus titulares delegan en organizaciones creadas al efecto, la negociación de las condiciones en que sus obras, sus prestaciones artísticas o sus aportaciones industriales, serán utilizadas por los difusores y otros usuarios primarios, el otorgamiento de las respectivas autorizaciones, el control de las utilizaciones, la recaudación de las remuneraciones devengadas y su distribución o reparto entre los beneficiarios (Lipszyc, 1993).

La amplitud de las funciones que cumplen las entidades de gestión colectiva depende de la categoría y del género de derechos administrados, sin embargo, comprende al menos dos aspectos básicos: la recaudación y la distribución o reparto.

Gran parte de las utilizaciones de obras y productos culturales se cumplen a través de la ejecución pública de obras musicales en locales de baile, discotecas, restaurantes, etc., para ambientación en tiendas, empresas comerciales, oficinas, talleres, etc., "en vivo" o por medio de grabaciones sonoras, de la radiodifusión y de la distribución por cable; dela proyección o exhibición de obras cinematográficas y de la reproducción en video; de la reproducción reprográfica de obras impresas para usos personales y privados y de la copia doméstica de grabaciones sonoras y audiovisuales para usos personales (Lipszyc, 1993). 
Para el autor es imposible saber dónde, cuándo y cómo se están utilizando sus obras, frecuentemente la explotación tiene lugar en muchos países al mismo tiempo; para los difusores y usuarios sería imposible entrar en contacto directo con todos los autores, compositores y editores de obras musicales a fin de obtener autorización para utilizar dichas obras, convenir precios y condiciones de uso de las que difunden diariamente.

Cuando se trata de obras musicales, sobre las que habitualmente concurre pluralidad de titularidades y que son objeto de utilizaciones múltiples, simultáneas, fugaces y dispersas; su explotación, control y el ejercicio efectivo de los derechos que las leyes reconocen a los autores, solo puede lograrse a través de la gestión colectiva, sistema que presta servicio tanto al creador como al difusor.

Este sistema beneficia al autor que no tiene posibilidad real de realizar la administración individual de sus derechos, pues le demandaría gastos y no lograría igualar los resultados que se logran a través del sistema de gestión colectiva y del régimen de contratos de representación recíproca entre sociedades de autores de diferentes países.

Beneficia al difusor porque le permite acceder lícitamente a una gran cantidad de obras diferentes, negociar su utilización con los representantes de las asociaciones, sobre la base de tarifas uniformes, y realizar los pagos con la certeza de cancelar sus obligaciones (Lipszyc, 1993).

Así, la gestión colectiva de los derechos de ejecución pública, es la única opción válida para que el derecho de autor no quede reducido a una reglamentación, o a un derecho de simple remuneración, ya que ante las dificultades que presenta el ejercicio individual del derecho de autor, el sistema de licencias obligatorias constituye la única forma de evitar a los difusores la continua violación de la ley, utilizando las obras sin autorización de los autores (Lipszyc, 1993).

La administración colectiva resulta muy útil también respecto de otras formas de explotación de obras: reproducción mecánica, comunicación pública de obras dramáticas; realización de obras audiovisuales, edición de obras literarias y reproducción de obras artísticas; porque es muy difícil que los autores se encuentren preparados para discutir las condiciones de los contratos y para controlar y exigir su cumplimiento, con el consiguiente desmedro para sus derechos morales y patrimoniales. 
Si el titular de un derecho exclusivo puede ejercerlo por sí mismo, éste puede disfrutarse más plenamente. Así mismo, conserva el control de la difusión de su obra, puede adoptar decisiones sobre las condiciones económicas de su explotación, y también puede controlar el debido respeto de sus derechos morales y patrimoniales.

Con la administración colectiva, el control ejercido por los titulares de derechos sobre ciertos aspectos de su ejercicio se vuelve más o menos indirecto; pero, si el sistema de administración colectiva funciona adecuadamente, esos derechos mantendrán su carácter exclusivo y subsistirán en la forma más completa que permiten las circunstancias (Lipszyc, 1993).

Los derechos de autor en nuestra legislación se encuentran protegidos en la Ley 312 "Ley de Derecho de Autor Derechos Conexos", y contempla la figura de que las sociedades de gestión definida en el artículo 113 de la siguiente manera: Son Sociedades de Gestión las organizaciones de base asociativa sin fines de lucro, legalmente constituidas al tenor de la Ley 147 Ley General sobre Personas Jurídicas sin Fines de Lucro, para dedicarse en nombre propio o ajeno, a la gestión de Derecho de Autor o Derechos Conexos de carácter patrimonial por cuenta y en interés de varios de sus titulares o concesionarios en exclusiva.

Estas sociedades gozarán de los derechos y deberán cumplir las obligaciones que se expresan en este capítulo e inscribirse en el Libro de Control que lleva la Oficina Nacional de Derechos de Autor y Derechos Conexos, y en los términos previstos en él y a la vez quedarán sometidas al control y vigilancia de la citada oficina.

Con base en esta ley, se fundó el 2 de abril del año 2003 la primera entidad de gestión de Nicaragua, denominada Sociedad de Gestión Colectiva de Derechos de Autor y Derechos Conexos de Nicaragua "NICAUTOR", cuya personalidad jurídica le fue otorgada por la Asamblea Nacional, por el Decreto No. 3731, publicado en La Gaceta, Diario Oficial No. 26 del 26 de febrero de $2004^{10}$.

10 En La Gaceta, Diario Oficial número 213, del 2 de noviembre de 2004, fue publicada la Escritura de Constitución y Constancia de inscripción del Departamento de Registro y Control de Asociaciones del Ministerio de Gobernación. 


\section{Naturaleza jurídica}

Con independencia del carácter y la forma jurídica de las organizaciones de gestión colectiva de derechos de autor, su objeto principal es defender los intereses de carácter personal (derecho moral) y administrar los derechos patrimoniales de los autores sobre sus obras de creación (Lipszyc, 1993).

Históricamente, la gestión colectiva del derecho de autor y de los derechos conexos ha nacido y se ha desarrollado a través de entidades de carácter privado, sin ánimo de lucro, conformadas por autores y otros titulares de derechos, con el objeto de administrar los derechos de que son titulares sus miembros y representados, brindar por su intermedio seguridad social a sus miembros y servicios de promoción cultural y aún, de solución de controversias entre sus miembros a través de la conciliación y la amigable composición.

La determinación exacta de cuál es la naturaleza jurídica de las sociedades de gestión colectiva, corresponde realizarla a la luz de la normatividad de cada país en particular. Sin embargo, existe la tendencia a identificar estas sociedades bajo la figura de la sociedad civil (SACD y SACEM de Francia han asumido este carácter desde su fundación).

En Colombia, la ley no definió cuál es la naturaleza jurídica que corresponde a las sociedades de gestión colectiva de derecho de autor y de derechos conexos. Ya como una sociedad civil, o como una asociación sin ánimo de lucro, han existido posiciones encontradas, las que se ven reflejadas en la jurisprudencia mediante fallos de los altos tribunales, así: "La Corte Constitucional de Colombia, ...identificó a las sociedades de gestión colectiva de derecho de autor y de derechos conexos con las sociedades civiles, reguladas por los artículos 10 a 50 de la Ley 44 de 1993. A pesar de que el artículo 10 las define como entidades sin ánimo de lucro, ...lo cierto es que la posterior regulación legal muestra que se trata de sociedades con contenido esencialmente patrimonial (Zapata López)”.

El artículo 5 de los Estatutos de la CISAC $^{11}$ dispone que por sociedad de gestión se entiende cualquier organismo que:

11 CISAC, Confederación Internacional de Sociedades de Autores y Compositores. 
i) proclame en su objeto y asegure efectivamente la promoción de los intereses morales de los autores y la defensa de sus intereses patrimoniales; $y$

ii) cuente con un dispositivo eficaz de recaudación y reparto de los ingresos a título de derecho de autor y asuma total responsabilidad sobre las operaciones correspondientes a la gestión de los derechos a él confiados; y

iii) no administre también, salvo como actividad secundaria, los derechos de los artistas intérpretes o ejecutantes, de los productores de fonogramas, de los organismos de radiodifusión o de otros titulares de derechos. (Lipszyc, 1993).

En la legislación comparada no hay soluciones uniformes en lo atinente a la naturaleza jurídica de las sociedades de administración colectiva de derechos intelectuales, algunas se limitan a contemplar solo el funcionamiento de dichas organizaciones y definir sus atribuciones.

Tampoco los convenios internacionales, ni las agrupaciones o confederaciones de dichas entidades, ayudan a dilucidar el problema de la naturaleza jurídica de esas organizaciones, como la CISAC que se limita a señalar que las sociedades de autores, sea cual fuere su forma jurídica, son organismos de administración de los intereses patrimoniales de los autores y sus derechohabientes. No son organizaciones comerciales, ni empresas que persiguen fines de lucro... (Antequera Parilli, Tomo II, 1998)

En una primera redacción del estatuto tipo de las sociedades de gestión se enfatizó el enfoque de sociedades privadas, pero ante las preferencias de países africanos de crear oficinas o agencias de derecho público se convocó a un grupo de expertos y en París en el año 1980, se expresó la inclinación mayoritaria de la existencia de sociedad de derecho privado, pero acogiendo la solicitud de poner a disposición de los países dos textos distintos, uno para las oficinas de derecho público y otro para organizaciones privadas, dejando a los Estados la escogencia, sin excluir la forma de sociedades cooperativas, mixtas u otras fórmulas (Antequera Parilli, Tomo II, 1998).

En defensa del criterio de entidades de derecho público es por la posibilidad de lograr mayores recaudaciones con el apoyo gubernamental que podrían tener, para los casos de grupos pequeños de autores, 
artistas o productores nacionales, sin los recursos necesarios para los gastos iniciales; o bien, cuando los principales usuarios como la radio y televisión fueran estatales, la entidad de gestión oficial estaría en mejor situación para negociar e imponer el pago de las remuneraciones correspondientes. En sentido contrario, se señala el peligro de intervencionismo del Estado, que además de posibilitar interferencias al derecho a la libertad de expresión, podría permitir ciertas situaciones ventajosas a ciertos titulares.

Por otro lado, no existiría garantía de que una administración estatal sea más efectiva, o bien que no se convierta en un instrumento burocrático de escaso rendimiento, que se desvirtúen los fines de la agencia por la intromisión de factores ajenos al intelectual, o que la administración pública cuente con los recursos humanos especializados en un área que no le es propia.

El estatuto tipo también contempló modelos de sociedad privada, el cual admite la posibilidad de que el legislador nacional la someta a la vigilancia de un ministerio o de otro organismo estatal. Esta opción ha sido acogida en la mayoría de países europeos, en Estados Unidos y América Latina, y responde a la aspiración de los creadores, artistas y productores de administrar su propio derecho (Antequera Parilli, Tomo II, 1998, p. 690).

El modelo de sociedad privada no excluye:

- Que pueda ser sometida a la fiscalización o vigilancia del Estado, lo que ofrecería mayores garantías a los asociados y a los usuarios de las obras, interpretaciones o producciones,

- Que la ley y su reglamento contengan normas específicas en cuanto a las formalidades relativas a la constitución de una entidad de gestión, órganos estatutarios, deberes y atribuciones de los asociados, documentación que deben elaborar, depositar o registrar y otros requisitos,

- Que la legislación nacional atribuya a una organización de gestión colectiva la exclusividad en la administración de los derechos económicos de los autores, o de una parte de ellos.

- Que la fijación de tarifas para el uso de su repertorio, esté revestida del mismo imperio u obligatoriedad que tendría si surgiera de una entidad de derecho público (Antequera Parilli, Tomo II, 1998). 
- Si se considera la entidad de gestión colectiva como entidad de derecho privado, se estimaría como ente de carácter asociativo distinto de quienes lo integran, con un consenso de voluntades en su creación, con un conjunto de relaciones que nacen en virtud de la creación de la persona jurídica y se persigue un objetivo común.

Si bien algunas legislaciones admiten la constitución de organizaciones de gestión colectiva como sociedades, incluso mercantiles, se afirma que como tales no lo son porque no hay aportes de capital por los miembros, pues éstos se limitan a otorgar a la entidad la administración de sus derechos económicos, pero que no dejan de pertenecerle.

Además, por lo general, están obligadas a admitir a todos los autores, artistas o productores quelo soliciten, cuyas obras puedan ser susceptibles de utilización por cualquier medio o modo de explotación. En los casos de entidades con facultades exclusivas de administración de derechos, la obligación de asumir la gestión es todavía mayor, incluso de aquellos titulares que no deseen pertenecer a esa entidad como miembros.

Igualmente administra los derechos de quienes no pertenecen a ella, como los autores, artistas o productores extranjeros, con cuyas sociedades mantengan contratos de representación recíproca. La distribución de las remuneraciones no está en función del número o importancia de las obras, interpretaciones o producciones cuya administración les fue conferida, sino a los provechos que se deriven de su utilización.

No existe un fin lucrativo, pues no hay ganancias, ni reparto de utilidades, la entidad solamente puede retener un porcentaje de lo recaudado para sostener sus gastos de administración y cumplir con otros objetivos como es la protección social de sus miembros. (Antequera Parilli, Tomo II, 1998).

En conclusión para un sector de la doctrina, las entidades de gestión son asociaciones sui generis que deben ser objeto de una regulación detallada, la ley o su reglamento debe establecer ciertos requisitos en cuanto a la solicitud de su funcionamiento, régimen de fiscalización, normas administrativas, órganos estatutarios, deberes y atribuciones, formalidades registrales especiales, rendición de cuentas, reglamentaciones de reparto, y otras que adapten su carácter asociativo 
a las particulares características de la gestión económica de los derechos administrados (Antequera Parilli, Derecho de Autor, Tomo II, 1998).

\section{Su régimen legal}

El Convenio de Berna, para la protección de las obras literarias y artísticas, es la base de las modernas leyes de derecho de autor. De conformidad con el Artículo 9 del mismo, el autor de una obra literaria o artística tiene el derecho exclusivo de autorizar o prohibir la reproducción de su obra "por cualquier procedimiento y de cualquier forma". La reproducción o copia puede realizarse de muchas formas, tales como:

- impresión

- fotocopia

- escaneado

- copia digital (por ejemplo, en CD y en DVD)

- almacenamiento electrónico en bases de datos (Koskinen-Olsson, La Gestión Colectiva en el ámbito de la reprografía, 2005).

El derecho exclusivo a autorizar o prohibir la reproducción de una obra puede estar sujeto a limitaciones o excepciones bajo el Convenio. De conformidad con el mismo artículo 9 "Se reserva a las legislaciones de los países de la Unión la facultad de permitir la reproducción de dichas obras en casos especiales, con tal de que esa reproducción no atente a la explotación normal de la obra ni cause un perjuicio injustificado a los intereses legítimos del autor".

El ámbito de las excepciones y limitaciones también está restringido por el Acuerdo sobre los aspectos de los Derechos de la Propiedad Intelectual relacionados con el Comercio (ADPIC), administrado por la Organización Mundial del Comercio (OMC). El artículo 13 del ADPIC establece que: "Los Miembros circunscribirán las limitaciones o excepciones impuestas a los derechos exclusivos a determinados casos especiales que no atenten contra la explotación normal de la obra ni causen un perjuicio injustificado a los intereses legítimos del titular de los derechos (Koskinen-Olsson, La gestión colectiva en el ámbito de la reprografía, 2005)".

El mismo principio se expresa en el artículo 1o del Tratado de la OMPI sobre Derecho de Autor de 1996. Como consecuencia de esta regulación, 
las limitaciones o excepciones únicamente se permiten si se cumplen tres condiciones, a saber:

- Las limitaciones y excepciones pueden aplicarse solo en "ciertos casos especiales", y no deben ser generalizadas;

- No pueden atentar a la explotación normal de la obra;

- No pueden causar un perjuicio injustificado a los intereses legítimos del titular del derecho.

Los criterios anteriores para la restricción de los derechos exclusivos son acumulativos, es decir, la aplicación de las limitaciones o excepciones sólo es posible si se cumplen los tres simultáneamente. Los impactos de la fotocopia pueden ser distintos a los de la copia digital; en consecuencia, la solución legislativa adecuada puede ser diferente para cada caso.

En la legislación de la Unión Europea, la Directiva relativa a la armonización de determinados aspectos del derecho de autor y derechos afines a los derechos de autor en la sociedad de la información, trata de los derechos de reproducción y las posibles excepciones y limitaciones.

Los artículos relevantes son los siguientes:

- Derecho de reproducción (artículo 2);

- Excepciones y limitaciones (artículo 5).

El preámbulo 35 de la Directiva incluye directrices para los legisladores nacionales sobre este nuevo concepto de compensación equitativa. Establece: "En determinados casos de excepciones o limitaciones, los titulares de los derechos deberían recibir una compensación equitativa para recompensarles adecuadamente por el uso que se haya hecho de sus obras". La Directiva deja a los Estados miembros la determinación de la forma, las disposiciones detalladas y el nivel de dicha compensación equitativa.

La legislación nacional del derecho de autor en los diferentes Estados debe estar armonizada con las normas comúnmente aceptadas a nivel internacional y regional. Dado que el derecho de reproducción es un derecho exclusivo, las limitaciones o excepciones no deben enturbiar este principio básico en la legislación nacional.

Igualmente, la legislación nacional puede incluir usos libres, es decir, sin necesidad de consentimiento y sin remuneración, sólo en casos especiales establecidos. La existencia de disposiciones generales 
sobre "uso justo" o "prácticas comerciales leales" pueden dar lugar a situaciones en las que la concesión de licencias o la remuneración se hacen prácticamente imposibles. Debe existir un equilibrio entre los intereses legítimos de los titulares de los derechos y los de los usuarios. Las organizaciones de gestión juegan un papel importante en la sociedad, facilitando un acceso rápido y legal a la información de una forma relativamente barata. También preservan un entorno propicio a la creatividad, proporcionando una remuneración justa a los titulares de los derechos así como incentivos para la creación futura (KoskinenOlsson, La Gestión Colectiva en el ámbito de la reprografía, 2005).

En nuestro país las sociedades de gestión colectiva deben constituirse de conformidad con la Ley General sobre Personas Jurídicas sin fines de lucro (Ley 147) y deberá inscribirse en el Libro de Control que llevará la Oficina Nacional de Derechos de Autor y Derechos Conexos, tal como lo establece la Ley No. 312, Ley de Derecho de Autor y Derechos Conexos, en su artículo 113 (Bendaña Guerrero, 2006).

Para que se conceda el Registro, según el artículo 114 LDA, la sociedad de gestión deberá:

1. Constituirse según la Ley General sobre Personas Jurídicas sin fines de lucro

2. Que sus Estatutos cumplan las disposiciones legales,

3. Si de los datos aportados y de la información practicada se desprende que la organización solicitante reúne las condiciones necesarias para asegurar una gestión sana y eficaz.

En el Reglamento de la Ley No. 312, señala el artículo 30 que también deberá precisarse con claridad su objeto o fines de acuerdo a:

1. Por rama o categoría de creación de obras,

2. Por categoría de titulares de derechos conexos,

3. Por modalidad de explotación, cuando concurran en su titularidad varias categorías de creación de obras o de titulares de derechos conexos, y siempre que la naturaleza de los derechos encomendados a su gestión así lo justifique ${ }^{12}$.

12 Decreto 22-2000. Reglamento de la Ley de Derechos de Autor y Conexos. Publicado en La Gaceta, Diario Oficial No. 84 del viernes 5 de mayo del 2000. 
La valoración de los requisitos de la sociedad están establecidos en los artículos 115 y 116 LDA, según los cuales deben ser requisitos de los Estatutos:

1. La denominación no podrá ser idéntica a la de otras sociedades de gestión, ni semejante que pueda inducir a confusión.

2. En su objeto o fines, se especificarán los derechos delos administrados, no pudiendo dedicar su actividad fuera del ámbito de la protección de los derechos de autor o conexos.

3. Las clases de titulares y concesionarios exclusivos de derechos comprendidos en la gestión y en su caso, las distintas categorías de aquellos a efectos de su participación en la administración de la entidad.

4. Expresión de las condiciones para la adquisición y pérdida de la calidad de socio y las reglas generales a las que se ajustará el contrato de adhesión a la sociedad. Sólo podrán ser socios los titulares o concesionarios exclusivos de los derechos administrados.

5. Los deberes y derechos de los socios y su régimen disciplinario y, en particular, el de votación, que tendrá en cuenta criterios que limiten razonablemente el voto plural.

6. Los órganos rectores de la sociedad, los cuales como mínimo serán la Asamblea General, la Junta Directiva y el de Vigilancia.

7. Determinación del destino del patrimonio o activo negó resultante de la liquidación de la sociedad en caso de disolución, cuyo patrimonio no podrá ser objeto de reparto entre los socios.

8. Así mismo, de conformidad con el artículo 120 LDA, las sociedades de gestión deberán establecer en sus estatutos las disposiciones adecuadas para asegurar una gestión libre de influencias de los usuarios de su repertorio, y para evitar una injusta utilización preferencial de las obras o prestaciones comprendidas en este (Bendaña Guerrero, 2006).

Tal como lo establece el art. 117 LDA, el registro de una sociedad de gestión se publicará en La Gaceta, Diario Oficial. Así mismo, el registro publicará una relación de las sociedades de gestión autorizadas (Bendaña Guerrero, 2006).

\section{Características fundamentales}

Los derechos de los autores sólo pueden administrarse en forma colectiva si están debidamente contemplados en la legislación, pues no tendría sentido considerar la gestión de derechos de radiodifusión, por 
ejemplo, si no existe la certeza de que las emisoras de radio y los canales de televisión, están obligados a pagar regalías a los autores de las obras que emiten.

Además, la gestión colectiva del derecho de autor sólo se hará con éxito si se confiere el mismo nivel de protección a las obras nacionales y extranjeras; es decir, si el país se compromete a tratar las obras nacionales y extranjeras en términos de igualdad, tras adherirse a instrumentos internacionales. Si las obras extranjeras no gozan de protección, los usuarios no se someterán a la obligación de pagar regalías por las obras nacionales, y a su vez, si no se da protección a las obras nacionales, una sociedad de derecho de autor terminará por convertirse en representante de intereses extranjeros y nunca logrará el pleno reconocimiento en el país en el que desarrolla sus actividades (Uchtenhagen, 2005, pág. 9).

Ampliamente se ha demostrado que la gestión colectiva del derecho de autor no prospera si la sociedad no logra controlar todos los derechos de un determinado ámbito con respecto a una cierta categoría de obras. La sociedad debe llevar a cabo la gestión del denominado "repertorio mundial” de música, literatura, obras dramáticas, etcétera. Una única sociedad de derecho de autor por cada derecho y por cada categoría de obras en un país, la coloca en una situación de monopolio de hecho o de derecho, porque si existieran varias sociedades para los mismos derechos y las mismas obras, no sería posible demarcar con precisión el límite de sus actividades.

En principio es admisible la gestión paralela del derecho de autor y de los derechos conexos por dos sociedades distintas. Sin embargo, si ambas deben tratar con los mismos usuarios, éstos exigirán una gestión coordinada de ambos tipos de derechos, demanda que en muchos países ha impulsado la cooperación conviniendo establecer un mecanismo común de concesión de licencias y de recaudación de regalías (Uchtenhagen, 2005).

La sociedad de derecho de autor deberá contar con un nivel mínimo de ingresos para llevar adelante su trabajo con eficacia y eficiencia, en particular, cuando se refiere a un amplio repertorio internacional, lo que supone una extensa red de distribución y de pagos, con los consiguientes gastos de administración. 
Los ingresos estimados de una sociedad de derecho de autor se calculan pronosticando el volumen previsto de regalías por recaudar o, sobre la base de los aranceles medios, ya sea a partir del ingreso per cápita en otros países con situaciones semejantes.

Debe determinarse el personal que se encargará de la recaudación y la compilación de los documentos necesarios para realizar con eficacia la distribución y el pago, con la correspondiente estimación de su salario y la previsión de los gastos generales a partir de esos cálculos.

Si los costos no superan el 30\% de los ingresos procedentes de la gestión de derechos de interpretación o ejecución y de radiodifusión, o el 25\% de los ingresos procedentes de la gestión de los derechos de reproducción, puede considerarse que la gestión será económicamente autónoma y la sociedad viable.

La posición que adopte el gobierno de un país antela decisión de establecer una nueva sociedad de derecho de autor es importante, esto porque las actividades abarcan obligaciones que también son de competencia del Estado, pues tanto el Estado como la sociedad de derecho de autor deben garantizar el ejercicio de distintos derechos contemplados en la ley (Uchtenhagen, 2005).

Las actividades de las sociedades de derecho de autor se relacionan con las de varias instituciones estatales, como las empresas nacionales de radio y televisión, los programas culturales, los registros estatales, las leyes y los reglamentos. De allí la necesidad de asegurarse desde el comienzo que el Estado esté de acuerdo con el principio de la gestión colectiva del derecho de autor y que esté dispuesto a amparar sus actividades.

La administración de un "repertorio mundial" y la correspondiente posición de monopolio, de hecho o de derecho, de la sociedad de derecho de autor la colocan al alcance de la legislación sobre competencia desleal, por lo que la aplicación de esa legislación a la gestión colectiva del derecho de autor debe evitarse a toda costa, y la solución consistirá en que el Estado controle la sociedad de derecho de autor mediante una legislación especial, excluyendo la aplicación de normas generales sobre competencia desleal. 
Asimismo, para obtener el apoyo del Estado deberá garantizarse la posibilidad de inspeccionar y supervisar las operaciones de la sociedad de gestión, porque una declaración de las autoridades en el sentido de que las operaciones de la sociedad de derecho de autor se han llevado de manera correcta, es de gran valor en cualquier Estado (Uchtenhagen, 2005).

La tarea más importante para una sociedad de derecho de autor es pagar importes equitativos a los autores y editores por la utilización de sus obras. Esta tarea no se realiza si dicha sociedad, en lugar de efectuar pagos, constituye fondos y reservas y con esos recursos persigue otros objetivos (Uchtenhagen, 2005).

Que los importes pagados sean equitativos dependerá del cálculo de los aranceles, que será la base de las regalías o de la remuneración pagada por los usuarios. La orientación al respecto surge de la utilización en el plano nacional y de las normas internacionales. En particular:

- la "regla del 10\%" conforme a la cual los autores y los editores tienen derecho a un décimo del total de los ingresos obtenidos por los usuarios de las obras como consecuencia de la explotación de las mismas;

- la "regla pro rata temporis", conforme a la cual el 10\% que corresponderíaalosautoresyloseditoressereduceproporcionalmente cuando se explotan conjuntamente obras protegidas y obras libres;

- la "regla del ballet" conforme a la cual el 10\% que correspondería a los autores y los editores también se reduce proporcionalmente cuando se explotan varias obras al mismo tiempo (Uchtenhagen, 2005).

La deducción de costos de hasta un 30\% para la administración de derechos de interpretación o ejecución y radiodifusión, y hasta un $25 \%$ para la administración de derechos de reproducción, puede justificarse a condición de que con las actividades de distribución se logre llevar cuentas periódicas, detalladas e individuales para cada autor y editor.

Cuando las obras se explotan, la sociedad de derecho de autor debe informar a los autores y los editores de la manera más detallada posible, acerca de la utilización de esas obras y su nivel de aceptación por el público. Esa información posibilita, en particular a los editores, evaluar su riesgo al publicar nuevas obras. Con este fin, los pagos a los autores 
y los editores no deberían simplemente indicar cuantías globales, sino también suministrar información acerca de los importes generados por cada una de las obras (Uchtenhagen, 2005, pág. 14).

Además, se recomienda que las cuentas relativas a cada obra indiquen el ámbito de utilización más frecuente, para ello las sociedades de derecho de autor deben reclamar y obtener de los usuarios las listas o planillas de transmisión en las que figuran las obras interpretadas, emitidas o reproducidas, y esas listas y planillas de transmisión constituirán la base de las actividades de distribución.

En la actualidad, gracias a la tecnología, con emisiones satelitales cuyos programas se reciben en continentes enteros, la presencia cultural de un país depende de su capacidad de poner a disposición las mejores obras de sus autores, en un formato de utilización rápida y elevada calidad. Ante la facilidad de acceso a las obras, la sociedad de derecho de autor cumple una importante función, pues identifica rápidamente qué obras podrían ser adecuadas para su promoción internacional, presta asistencia a los autores y editores y dispone sus esfuerzos para intentar explotar sus obras en todo el mundo.

Para establecer una sociedad de derecho de autor, se aconseja adoptar un enfoque gradual, es decir que inicialmente sólo se lleven a cabo actividades de concesión de licencias y recaudación de regalías en el propio país, delegando las actividades de distribución y de pagos, más exigentes desde el punto de vista técnico, en una sociedad filial extranjera.

Una filial, a diferencia de una sociedad independiente, difícilmente se esforzará por obtener listas o planillas de transmisión donde consten las obras interpretadas, emitidas o reproducidas, a partir de las cuales pueda establecerse la "vida" del repertorio nacional. Esta inercia es una característica típica de toda filial y eso le ahorra una cantidad de actividades de distribución. Sólo una sociedad de derecho de autor nacional y autónoma puede, por lo tanto, satisfacer las necesidades de los autores y los editores nacionales (Uchtenhagen, 2005).

Una vez determinados los prerrequisitos para el establecimiento de una sociedad de derecho de autor, debe comenzar las actividades de la sociedad, con intervención desde el comienzo, de los autores y los editores para evitar descuidar los intereses de los titulares de derechos, con la 
designación de un director encargado y que actúe de acuerdo con las autoridades gubernamentales del país, para contar con el reconocimiento y el apoyo estatal a sus actividades (Uchtenhagen, 2005).

En nuestro país según la Ley No. 312 "Ley de Derecho de Autor y Derechos Conexos”, el régimen legal de las sociedades de gestión colectiva, presenta las siguientes características (Bendaña Guerrero, 2006, pág. 197):

- No es una actividad libre, la constitución de una entidad o sociedad de gestión es un proceso tutelado por la administración,

- De naturaleza necesariamente no lucrativa,

- Asume obligaciones con los socios, tales como:

* La de aceptar la administración de los derechos de autor y derechos conexos que le sean encomendados directamente de acuerdo con su objeto o fines, así lo establece el artículo 119 LDA.

* La duración de los contratos de gestión no será superior a dos años, pero son indefinidamente renovables.

* La realización de actividades o servicios asistenciales en beneficio de los socios, así como promover otras de carácter cultural, según el artículo 123 LDA.

* El reparto de los derechos deberá hacerse de acuerdo con un sistema que excluya la arbitrariedad, y que se encuentre previsto en los Estatutos. Y ese reparto debe asegurar a los titulares una participación en la recaudación proporcional a la utilización de sus obras.

- Asume obligaciones hacia los usuarios o clientes, tales como:

* Las entidades de gestión deben contratar con quien lo solicite y otorgar, en condiciones razonables y bajo remuneración, una licencia no exclusiva de los derechos que gestione.

* Deben, además, establecer tarifas generales que fijen los precios a los que se sujetan las distintas explotaciones de su repertorio. Estas tarifas deben prever reducciones para las entidades que carezcan de fines lucrativos ${ }^{13}$.

* Están obligadas a negociar dichos aranceles con asociaciones de usuarios de su repertorio, siempre que lo soliciten y sean representativas del sector correspondiente la ley contempla las tarifas generales como un mecanismo de defensa de los

13 En La Gaceta, Diario Oficial No. 223 del 17 de noviembre de 2005, fueron publicados los Aranceles General de NICAUTOR. 
usuarios, quienes, con la mera reserva de esas cantidades o de su consignación judicial, obtienen, ministerio legis, autorización para su actividad. Este sistema automático de autorización, no es aplicable a los casos de las obras dramáticas, dramático-musicales o coreográficas, ni a las utilizaciones en que se pretenda una utilización singular de una obra (Bendaña Guerrero, 2006).

\section{Dinámica de la actuación de las sociedades de gestión colectiva}

Las entidades de gestión colectiva están legitimadas en los términos que resulten de sus propios estatutos y de los contratos que celebren con entidades extranjeras, para ejercer los derechos confiados a su gestión $\mathrm{y}$ hacerlos valer en toda clase de procedimientos administrativos y judiciales (Antequera Parilli, Tomo II, 1998).

Esta norma tiene diversos antecedentes, fácticos y legislativos, los primeros antecedentes proceden de la experiencia en algunos países latinoamericanos:

1. Existían sociedades que de conformidad con sus estatutos, se habían constituido para administrar determinada modalidad de explotación, sin embargo, pretendían fijar tarifas y efectuar recaudaciones por géneros distintos,

2. La presencia de dos o más entidades de gestión competidoras al administrar el mismo género, hizo que todas ellas pretendieran ostentar la representación del repertorio extranjero.

3. Les bastaba una declaración unilateral, incorporada a sus estatutos, donde proclamaban representar el repertorio nacional einternacional.

4. Así, una de ellas, sin haber declarado contrato de representación con ninguna sociedad extranjera, fijaba entonces una tarifa baja, en relación con aquella que sí tenía la representación de las sociedades de gestión de los demás países, con lo cual se colocaba a muchos usuarios que utilizaban un catálogo, nacional e internacional, en la posición cómoda de cancelar a la que tenía el arancel inferior y alegar la buena fe en el pago y el uso realizados.

5. El usuario honesto no tenía la posibilidad de conocer de la existencia de esos contratos, y por tanto, tampoco podía alegar y probar, que una de las sociedades actuantes no representaba el repertorio que decía administrar, sino la otra, o simplemente ninguna (Antequera Parilli, Tomo II, 1998). 
Sobre la base de esos elementos de hecho, resultaba armónico con la realidad la exigencia a las sociedades de gestión colectiva de inscribir en el Registro de la Producción Intelectual, no solamente sus estatutos y reglamentos internos, sino también los contratos celebrados con entidades extranjeras de la misma naturaleza, sin lo cual tales contratos no tendrían efectos frente a terceros.

En cuanto a los antecedentes legislativos, los mismos proceden de la ley española, quien a su vez se inspiró en la francesa, las que al respecto señalan que es necesario y suficiente que los estatutos se refieran al ejercicio del derecho que se trata de hacer valer, para que la acción ejercitada por la sociedad de gestión sea admitida, y que esa representación o actuación con base a los estatutos comporta la no mención de las personas interesadas, y con ella, la supresión del deber de acreditar la relación que exista entre el que acciona y el interesado, autores y sus derecho-habientes.

La ley española, a los efectos de trasponer el contenido de las directivas europeas, aprovechó la circunstancia para acentuar el espíritu y propósito de la norma ya existente, al agregar un párrafo que textualmente dice: "la entidad de gestión estará obligada a aportar al proceso copia de sus estatutos, así como certificación acreditativa de su autorización administrativa. El demandado podrá oponer exclusivamente, acreditándolo debidamente, la falta de representación de la actora, la autorización del titular del derecho exclusivo, o el pago de la remuneración correspondiente (Antequera Parilli, Tomo II, 1998)".

Tales antecedentes dieron lugar a la normativa andina, y añadieron una frase por la cual no solamente se menciona a los estatutos de la entidad, sino también a "los contratos que celebren con entidades extranjeras." De tal agregado no puede interpretarse que la sociedad actuante deba probar la autoría y la titularidad de los derechos, sobre cada una de las obras administradas por la sociedad extranjera, con la cual la nacional mantiene contratos de representación, esto resultaría absurdo, porque dichos contratos no detallan obras, sino que se confían repertorios, y las licencias no exclusivas que otorgan las entidades de gestión, tiene por objeto repertorios y no obras individualmente consideradas, salvo casos de excepción. 
La finalidad perseguida por el legislador fue la de facilitar su tarea a las sociedades de gestión, y la referencia a los contratos de representación con entidades extranjeras, no debe entenderse al margen de esa finalidad. Normalmente, es el usuario no licenciado quien se encuentra bajo una presunción de ilicitud, de modo que a él le corresponde desvirtuarla y no a la sociedad de gestión (Antequera Parilli, Tomo II, 1998).

En la legislación nacional, una vez autorizadas las sociedades de gestión, estarán legitimadas para ejercitar los derechos objeto de su gestión y hacerlosvalerentodaclasedeprocedimientosadministrativosyjudiciales, sin aportar más título que sus propios estatutos, presumiéndose, salvo prueba en contrario, que tales derechos les han sido confiados por sus respectivos titulares o concesionarios en exclusiva. (Bendaña Guerrero, 2006).

El artículo 118 de la Ley 312 establece:

Una vez autorizadas, las sociedades de gestión estarán legitimadas para ejercitar los derechos objetos de su gestión y hacerlos valer en toda clase de procedimientos administrativos y judiciales sin aportar más título que sus propios estatutos, presumiéndose, salvo prueba en contrario, que tales derechos les han sido confiados por sus respectivos titulares o concesionarios en exclusiva.

Los documentos que emite la sociedad de gestión para efectos de cobro por la utilización de obras artísticas y/o musicales, literarias, científicas; efectuado a personas naturales o jurídicas constituyen título ejecutivo, y se sustentarán por la vía ejecutiva. Caben únicamente las excepciones de pago y la no utilización de obras protegidas.

La sociedad de gestión está facultada para solicitar a la autoridad judicial competente, la suspensión de comunicación pública o presentaciones de obras artísticas y/o musicales protegidas conforme esta Ley, mientras esté pendiente el pago de aranceles correspondientes ${ }^{14}$.

Este artículo es tomado de la Ley de Propiedad Intelectual española, quien a su vez lo toma de la Ley francesa de 11 de marzo de 1957, cuya

14 Los dos últimos párrafos de este artículo fueron adicionados por la Ley No. 577, Ley de Reformas y Adiciones a la Ley No. 312, Ley de Derechos de Autor y Derechos Conexos, del 22 de marzo de 2006, publicada en La Gaceta Diario Oficial No. 60 del 24 de marzo de 2006. 
interpretación acerca de la legitimación de las sociedades de gestión, es debido a que cuando se trate de reclamos masivos, tendría que acreditar las representaciones de cada uno de los autores que representa, los que podrían ser muchísimos y de allí que bastará a la sociedad de gestión estar autorizada para tener legitimidad de representación de sus asociados, en los términos que resulten de sus propios estatutos. La carga de la prueba, deberá aportarla quien niegue el derecho de representación de la sociedad de gestión.

Esto significa que las sociedades de gestión no tienen necesidad de presentar documento alguno en que conste que tales derechos les han sido confiados. Esta facultad es discriminatoria en perjuicio de los demandados, puesto que a éstos les sería mucho más difícil probar que la sociedad de gestión no ostenta la representación de los derechos que dice tener conferidos. Rompe de esta manera con el principio de legitimación procesal establecido en la norma procesal civil nacional, artículo $1029 \operatorname{Pr}$ (Bendaña Guerrero, 2006).

\section{La representación}

La representación es un fenómeno que en este punto conviene traer a colación por razón de que los actos de las personas jurídicas denominadas "sociedades de gestión" se hallan directamente vinculadas a la dinámica por la que realizan su cometido más propio.

En todo caso, habrá de preguntarse si la actuación de las entidades de gestión constituye manifestación de una representación o de un simple mandato sin representación.

Aclaramos que pese a lo arduo que resulta para la doctrina el tema en cuestión, aquí, no entrando en mayores discusiones y plegándonos a las opiniones de la mejor doctrina (Guzmán García \& Herrera Espinoza, 2009), nos dedicaremos en pocas líneas a responder la pregunta antes planteada.

Efectivamente, la posibilidad de que alguien con su actuación repercuta en el ámbito jurídico de otra, trae a las mientes el tema de la representación, que -como bien expresa Santoro Pasarelli (1964, p. 329) - ha de entenderse como "una especie de sustitución legitimadora”. 
Y esa sustitución legitimadora implica entender que o bien existe entre las partes - entidad y autor - una relación jurídica que les involucra de forma relativa, es decir a través de recíprocas obligaciones -ámbito ad intra-; o que en cambio, entre dichas partes - entidad y autor- existe una relación que implica que el hacer de la entidad frente a terceros, repercuta directamente en el ámbito jurídico de la otra parte, es decir del titular de los derechos sobre la obra -ámbito ad extra-.

Así pues, si se acepta que la entidad realiza su actividad al amparo de un mandato, las consecuencias jurídicas de ello serían la simple regulación de la realización de prestaciones meramente relativas, esto es al amparo del contrato de "mandato". Sin embargo, si adoptamos la idea de que la entidad representa al titular de los derechos, entonces la consecuencia varía: la entidad actúa en nombre y por cuenta del titular.

El concepto y los principios de la representación que se contienen, sobre todo, en el Derecho Civil son aplicables a la materia mercantil. La necesidad de realizar simultáneamente negocios en lugares distintos se nota más intensamente en el campo del Derecho mercantil, cuya base es la contratación en masa. A esta necesidad satisface la institución de la representación jurídica como forma de cooperación, que permite el desdoblamiento de la personalidad y la actuación múltiple simultánea.

Así pues, hay representación cuando una persona celebra a nombre y por cuenta de otra un contrato (o en general un acto jurídico), de manera que sus efectos se producen directa e inmediatamente en la persona y patrimonio del representado, como si él mismo hubiera celebrado el contrato (o ejecutado el acto); se produce una relación obligatoria directa entre el representado y un tercero (Arce Gargollo, 2004). Y en el caso de las entidades de gestión parece existir representación, es decir sustitución legítima del titular que permite a la entidad "gestionar" es decir, realizar efectivamente las facultades subjetivas que incorpora el derecho de autor: Artículo 113 LDA: Son Sociedades de Gestión las organizaciones de base asociativa sin fines de lucro, legalmente constituidas al tenor de la Ley 147 "Ley General sobre Personas Jurídicas sin Fines de Lucro", para dedicarse en nombre propio o ajeno, a la gestión de Derecho de Autor o Derechos Conexos de carácter patrimonial por cuenta y en interés de varios de sus titulares o concesionarios en exclusiva. 


\section{Elementos:}

i) Los sujetos de la relación representativa son: el representado, a quien usualmente se denomina también principal o dueño del negocio, que es la persona cuyo interés gestiona el representante y en quien han de recaer, en definitiva, directa o indirectamente, los efectos de la gestión representativa. El representante, gestor o agente, que es la persona que actúa en interés o por cuenta del principal. El tercero con quien o ante quien se realiza la gestión representativa.

ii) El objeto de la representación es el negocio o asunto que el representante realiza en nombre y por cuenta del representado. La representación es admisible, en general, en la conclusión del contrato y de todo otro negocio a cuya naturaleza no repugne una sustitución de persona.

iii) La forma en que se otorga la representación es mediante el poder o procura.

La concesión del poder de representación, tanto en la forma explícita del apoderamiento como hallándose implícita en otro negocio, consiste en una declaración unilateral recepticia, o dirigida a la parte contraria, o, de cualquier modo destinada a serle conocida, con la cual se autoriza un acto ajeno de disposición, obligación o adquisición, recabando anticipadamente para sí las consecuencia que hayan de derivarse de ello (Arce Gargollo, 2004).

\section{Clases:}

Por su origen puede ser: voluntaria o legal. La primera deriva de la voluntad de las partes, principalmente del representado que autoriza previamente a que los efectos de los actos jurídicos celebrados en su nombre tengan efectos jurídicos en su esfera patrimonial. La legal tiene su fuente en la ley.

En la representación voluntaria una persona puede ocupar el lugar de otra de dos maneras: la primera es actuando en nombre y por cuenta del representado, llamada representación pasiva y, la segunda es realizando los actos en nombre propio, pero por cuenta del representado, que la llamada representación indirecta (Arce Gargollo, 2004).

La representación en el ámbito mercantil ofrece dos características importantes que la distinguen de la representación regulada por el Derecho civil, estas son: 
i) Es una representación más rígida en su contenido en cuanto que la ley, muchas veces, es la que fija las facultades del representante.

ii) El medio por el que se establece la relación representativa es mediante actos o circunstancias menos formales que los propios del Derecho civil (Arce Gargollo, 2004).

En la Ley de Derecho de Autor, se entiende por contrato de representación aquel en virtud del cual el autor o sus derechohabientes autorizan a un empresario el derecho de representación pública de una obra dramática, dramático-musical, coreográfica o pantomímica mediante remuneración, y el empresario se obliga a llevar a efecto de esa representación en las condiciones convenidas y con arreglo a lo dispuesto en esta ley ${ }^{15}$.

Dadas las características de este contrato, la Ley de Derecho de Autor permite que la cesión pueda revestir varias modalidades (Bendaña Guerrero, 2006):

- En cuanto al tiempo de cesión, el contrato puede concertarse por plazo cierto o por un número determinado de comunicaciones al público, en ambos casos el plano no podrá ser superior a dos años contados desde que el autor puso al empresario en condiciones de realizar la presentación.

- En cuanto a la forma de cesión, los derechos se pueden ceder en forma exclusiva o no exclusiva.

La duración no podrá exceder de cinco años ${ }^{16}$.

2. Modos de operar: negocio jurídico de derecho de autor

Antes de entrar a presentar los tipos de contratos que generalmente se celebran por las sociedades de gestión con sus representados y con los usuarios de los derechos de autor, haremos una breve relación del concepto general de contratos: ...resulta ser el negocio jurídico bilateral cuya finalidad radica en el intercambio de prestaciones de carácter patrimonial entre dos o más sujetos de derecho que ponen de común sus contrapuestos intereses (Guzmán García \& Herrera Espinoza, 2009).

15 Art. 66 Ley 312, Ley de Derecho de Autor y Derechos Conexos.

16 Art. 48 Ley No. 312, Ley de Derecho de Autor y Derechos Conexos. 
Los elementos que integran el contrato, que sirven como presupuestos necesarios para la conformación, nacimiento y validez del contrato son: consentimiento, objeto y causa, y la forma en casos expresamente determinados (Guzmán García \& Herrera Espinoza, 2009).

El consentimiento debe asociarse a la idea de autonomía de la voluntad, o mejor dicho a la de autonomía privada, en tanto dicha autonomía es el área de decisión que la ley permite a los sujetos de derecho, a los efectos que regulen entre sí de manera particular y dentro de las pautas que la misma impone, la regulación sobre sus intercambios de prestaciones obligacionales. El consentimiento contractual presenta como elementos integradores del mismo:

- Una pluralidad de sujetos,

- La capacidad legal de los mismos para la realización del acto,

- La existencia de voluntad, y

- La declaración de dicha voluntad de una forma legalmente relevante (Guzmán García \& Herrera Espinoza, 2009).

$\mathrm{Al}$ objeto del contrato se lo ha identificado con el objeto de la obligación, la prestación o comportamiento; con el fin; con las cosas o servicios; con la materia del negocio y con la obligación que por el contrato se constituye. El artículo 2473 de nuestro Código Civil establece: "Pueden ser objeto de contrato todas las cosas que no están fuera del comercio de los hombres, aun las futuras... pueden ser igualmente objeto de contrato todos los servicios que no sean contrarios a las leyes o las buenas costumbres." Así, puede decirse que objeto del contrato es todo bien susceptible de tráfico sobre el cual puede recaer la voluntad de las partes.

Para su existencia y validez, el objeto debe contar con algunos requisitos, los que de manera general son: posibilidad, licitud y determinabilidad; en su conjunto estos requisitos contribuyen a que el tráfico jurídico se realice sin alterar en ninguna forma la paz social (Guzmán García \& Herrera Espinoza, 2009).

El concepto de causa se aplica a todos los negocios jurídicos, con independencia de que sean patrimoniales o no, y que su causa está dada en algunos casos por el negocio mismo y por negocios antecedentes en otros tipos. La causa justifica su importancia para el mundo del derecho civil, a través de su función de control social de la autonomía privada, 
calificando como digna de tutela, cuando tal valoración sea necesaria, toda manifestación de voluntad, y en consecuencia, dotando de sentido y justificación, de manera general, a todo negocio jurídico (Guzmán García \& Herrera Espinoza, 2009).

Dentro de la estructura del negocio jurídico denominado contrato, la forma constituye la manera más propia en que se exterioriza la voluntad de darle vida al arreglo de privados interesados y tal "forma" debe resultar coherente, en todo aspecto, a la clase de negocio de que trate.

La forma debe entenderse en primer lugar, como el medio a través del cual se expresa lo que se quiere y en segundo término, puede verse la forma como la única manera que resulta adecuada, a los efectos de validez jurídica, para realizar la expresión de voluntad, lo cual se verifica a través de palabras, documentos escritos, etc (Guzmán García \& Herrera Espinoza, 2009).

Las relaciones jurídicas entre un titular de derecho de autor o conexo y la organización que administra sus aspectos económicos, son de diversa índole, según se trate de una entidad de derecho público o privado; que tengo o no derechos exclusivos o monopólicos para la administración del repertorio correspondiente, y en consecuencia exista una representación obligatoria o voluntaria.

La primera relación que salta a la vista es el mandato, porque se otorga a la entidad la representación y administración de los derechos de los autores, artistas o productores, no solamente nacionales, sino también los pertenecientes a sociedades extranjeras del mismo género, con las cuales la sociedad nacional mantenga contratos de representación o de cesión de repertorio (Antequera Parilli, Tomo II, 1998).

Ese mandato será voluntario, si la representación otorgada a la sociedad es facultativa del titular del derecho, quien podría reservase la administración de su propio derecho. Esta modalidad se produce cuando ninguna norma legal confiere a una entidad específica la facultad exclusiva de administrar el repertorio en un territorio determinado.

El alcance y las modalidades del mandato facultativo dependen de:

a) Que haya una sociedad unitaria administradora de todos los derechos sometidos a la gestión colectiva, o una por cada género o forma de utilización. En el primer caso el mandato se otorgaría a una única 
entidad, mientras que en el segundo, tratándose de un autor de obras de diversa naturaleza, podría otorgar mandato a varias de ellas, cada uno para la modalidad respectiva, o bien que dentro del mismo género exista una organización para la gestión de los derechos de comunicación pública y otra para los de grabación, o en que en una misma persona se reúnan varias titularidades, como el cantautor, quien podría otorgar diversas representaciones, una para la sociedad autoral y otra para la entidad de artistas intérpretes o ejecutantes.

b) Que los estatutos asociativos impongan como requisito para recibir el mandato, la gestión de todas las formas de explotación de las obras, interpretaciones o producciones que conformen su objeto social, o posibiliten al titular reservase la administración personal de algunas de esas modalidades, o ciertas autorizaciones de uso queden sometidas a su consulta previa, como ocurre, por ejemplo, con los autores dramáticos, en relación con la aprobación de los intérpretes o las condiciones técnicas de la representación.

c) Que las normas estatutarias permitan al titular del derecho administrado, conferir poder por territorios, de manera que al otorgar mandato a su sociedad nacional, pueda reservarse el derecho de confiarle la administración de su repertorio para otros territorios a sociedades extranjeras, en forma separada a los contratos de representación recíproca que celebren las entidades de diversos países entre sí; o las normas estatutarias impongan que el poder conferido faculta al ente asociativo para encomendar la gestión de su repertorio a las sociedades extranjeras con las cuales mantenga relaciones recíprocas (Antequera Parilli, Tomo II, 1998).

La relación jurídica derivada del mandato puede tener también un carácter obligatorio, en los siguientes casos:

1. Tratándose de una entidad de derecho público, la ley aplicable faculte a la organización para la gestión exclusiva y monopólica de los derechos de explotación en el territorio de su competencia, tanto del repertorio nacional como extranjero, de modo que autores, artistas y productores queden forzosamente representados por ella.

2. Siendo una entidad de derecho privado, exista una ley que le otorgue la facultad exclusiva de administrar todas o algunas modalidades de utilización en su territorio. 
3. La entidad mandataria tenga la facultad de sustituir y en efecto sustituya la representación otorgada por el titular de los derechos, en una entidad extranjera para que la represente en el área de su actividad.

4. El mandato de la sociedad nacional a la extranjera, en nombre de sus asociados o administrados, sea obligatorio, en razón del monopolio legal que esta última ostente en su territorio (Antequera Parilli, Tomo II, 1998).

La relación entre la asociación y sus miembros tiene características típicas, particularidades entre las que se destacan (Antequera Parilli, Tomo II, 1998, pág. 698):

a) Salvo en los casos de utilización individual de una obra, la entidad actúa para la defensa de todo un repertorio.

b) En consecuencia, y con la salvedad dicha, la asociación fija tarifas generales para la utilización global del catalogo administrado.

c) La representación del titular por el ente de gestión se rige de acuerdo a los estatutos y éstos, la mayoría de las veces, disponen que el asociado queda representado por aquélla para el ejercicio de sus derechos, por el solo hecho de su afiliación, sin ningún otro requisito o formalidad.

d) La legitimación de entidad para la defensa de ese repertorio deriva, en consecuencia, de las disposiciones legales especiales que la regulan y de lo contemplado en las normas estatutarias.

e) El porcentaje máximo de descuento por la administración de las obras, interpretaciones o producciones, pueden estar determinado por la ley, su reglamento o los estatutos, pero la deducción final queda sujeta a la aprobación del órgano estatutario competente.

f) Como los rubros administrados son objeto de reparto en períodos determinados, es posible que la entidad se encuentre autorizada para administrar las sumas pendientes de distribución, para el incremento del activo societario.

g) Adicionalmente al descuento por gastos administrativos, la asociación puede hacer una retención adicional para programas de protección social. Esa deducción también se efectúa sobre las remuneraciones que se remitan al extranjero, aunque los destinatarios de éstas no participen de los beneficios sociales en los cuales aquella es invertida.

h) Es admisible el sistema del voto ponderado, no en función del número de obras, interpretaciones o producciones confiadas a 
la entidad para su administración, sino de las remuneraciones generadas por ellas durante ejercicios anteriores.

i) La relación entre el titular del derecho y la entidad de gestión subsiste aunque la obra, interpretación o producción no genere en el futuro nuevas remuneraciones.

Los contratos de representación recíproca entre las sociedades de derecho de autor, de conformidad con el modelo de la CISAC, prevén la posibilidad de utilizar el 10\% del ingreso neto de la gestión de derechos de interpretación o ejecución y radiodifusión - previa deducción de los gastos administrativos - para actividades de bienestar social en favor de los autores y editores nacionales y de promoción cultural del repertorio nacional.

Se recomienda que esta práctica se institucionalice en el momento de establecer la sociedad y que se dé prioridad a los aspectos de bienestar social. Aunque parezca prematuro elaborar todo el plan de bienestar social ya en los primeros años, de hecho, nunca es demasiado temprano para establecer un fondo para gastos imprevistos con el fin de aliviar circunstancias difíciles, por ejemplo, tratamientos médicos urgentes y otros beneficios sociales (Uchtenhagen, 2005).

A menudo se pretende que la nueva sociedad de derecho de autor ponga en marcha inmediatamente, como "prioridad uno", sus actividades de lucha contra la piratería. Cabe hacer una advertencia: controlar el mercado (una actividad inevitable si han de identificarse copias piratas) es una tarea costosa que puede agotar muy rápidamente los medios financieros de una sociedad nueva. Por lo tanto, se recomienda que la lucha contra la piratería no se entable al comienzo, antes de que la sociedad de derecho de autor se haya establecido de manera firme en su función principal, y aun así, que la sociedad sólo emprenda tareas generales y el control de las condiciones de uso.

Ninguna sociedad de derecho de autor estará en condiciones de contactar a los usuarios, celebrar contratos y recaudar regalías o remuneraciones de todas las categorías de usuarios al mismo tiempo. A este respecto ha quedado comprobado que comenzar las actividades de recaudación en las organizaciones de radio y televisión ofrece ciertas ventajas, siendo la principal el hecho de que se trata de clientes importantes que pagan 
sumas considerables en regalías, por lo que no es necesario contar con una estructura compleja y costosa de recaudación (Uchtenhagen, 2005).

La gestión colectiva de los derechos patrimoniales ha resultado ser el único medio eficaz para que los titulares de derechos sobre las obras, interpretaciones o producciones, puedan controlar el uso de esos bienes intelectuales, así como de recaudar y distribuir las remuneraciones a que tiene derecho por su explotación.

Se hace más imperiosa la gestión colectiva, cuando se trata del repertorio extranjero, pues no podrían los autores, artistas y productores controlar la utilización de sus obras y producciones en el exterior, ni mucho menos tramitar directa e individualmente la recaudación y distribución de las remuneraciones respectivas.

Esta administración no solamente beneficia a los autores, artistas y productores, sino que facilita igualmentela situación de los usuarios delas obras, prestaciones y producciones, quienes en vez de tratar de localizar a cada autor, compositor, editor, arreglista, intérprete o productor, para obtener autorización de uso y cancelar la contraprestación debida, puede dirigirse a una entidad y a través de ella cumplir con las obligaciones derivadas de la explotación de todo un catálogo, nacional e internacional.

Se afirma que la gestión colectiva debe limitarse a las modalidades de explotación respecto de las cuales el titular del derecho se encuentra ante la difícil situación de controlar directamente el uso de su obra, interpretación o producción; de vigilar acerca del número de utilizaciones efectuadas, de verificar el monto de los ingresos obtenidos por el usuario a los efectos del cálculo de la tarifa y su recaudación, de identificar el repertorio efectivamente usado y de instrumentar los mecanismos para la distribución de las remuneraciones así recabadas (Antequera Parilli, Derecho de Autor, Tomo II, 1998).

Por ello, la gestión colectiva se ha dirigido especialmente a administrar aquellas formas de explotación en que se utiliza un catálogo o repertorio, o cuando la explotación es realizada por un gran número de usuarios. Sin embargo, el surgimiento de nuevas tecnologías que permitieron otras modalidades de explotación de las obras, de complicado o imposible control directo por parte de los autores, planteó la necesidad de ampliar el marco de acción de la gestión colectiva. 
Con la invención de las grabaciones gramofónicas, la difusión y venta a niveles millonarios de las reproducciones sonoras, la inclusión de numerosas creaciones en cada producción fonográfica y la circulación internacional de las obras así grabadas y difundidas, se amplió la gestión para extenderse a la administración de los derechos de reproducción mecánica, y de fijación sonora en soportes audiovisuales (Antequera Parilli, Tomo II, 1998).

Nuevas formas de uso de las creaciones y recientes innovaciones legislativas han extendido la labor de la gestión colectiva, hacia otros derechos o modalidades de explotación y entre ellos los siguientes:

- $\mathrm{El}$ «droit de suite», es decir, el derecho del artista plástico a obtener una participación en las reventas efectuadas sobre el soporte físico de su obra.

- El derecho de reproducción gráfica, sobre la importación o venta de los aparatos empleados para la reprografía y sobre las copias reprográficas realizadas.

- La remuneración compensatoria por la copia privada de obras en soportes sonoros o audiovisuales, así como sobre los aparatos utilizados para esa reproducción.

- Los derechos por el alquiler de copias de fonogramas y videogramas (Antequera Parilli, Tomo II, 1998).

Igualmente se encomendó a la gestión colectiva la administración del «dominio público oneroso», en ciertos países donde legislativamente existiera, o sea la contribución impuesta por la utilización de obras caídas en el dominio público, y cuyo producto ingresa a un patrimonio estatal separado, con destino al fomento de la actividad cultural, a la formación de nuevos artistas o a la protección social de los creadores.

El proyecto de disposiciones tipo de la OMPI, sugiere confiar a la gestión colectiva la administración del «droit de suite» y la correspondiente a los derechos reprográficos y al canon compensatorio por copia privada de obras sonoras o audiovisuales.

El impacto tecnológico ha posibilitado la formación de bases de datos donde se incorporan en forma íntegra o parcial diversas obras preexistentes, no solamente musicales, sino también las escritas, las figurativas, las llamadas producciones multimedia, y el ponerlas a disposición del público mediante la reproducción del contenido 
incorporado a la base, o a través del acceso por telecomunicaciones, incide sobre los derechos de reproducción, distribución y comunicación pública de las obras ingresadas a la base de datos, comprendidos los derechos de integridad y modificación (Antequera Parilli, Tomo II, 1998).

A la tradicional gestión colectiva de autores, compositores y editores de música y de autores de obras dramáticas, se unen la de escritores de diversos géneros, artistas plásticos, fotógrafos y editores literarios, a fin de controlar el uso e impedir utilizaciones no consentidas, y establecer mecanismos de autorización, fiscalización, recaudación y distribución. A ellos deben agregarse los derechos conexos al derecho de autor (Antequera Parilli, Tomo II, 1998).

Las entidades de gestión colectiva en general realizan las siguientes funciones:

a. Administrar los derechos de propiedad intelectual conferidos, con sujeción a la legislación vigente y a sus estatutos. Estas entidades ejercitan derechos de propiedad intelectual, bien de forma delegada por sus legítimos titulares, o bien por mandato legal (derechos de gestión colectiva obligatoria); persiguen las violaciones a estos derechos mediante un control de las utilizaciones; fijan una remuneración adecuada al tipo de explotación que se realice y perciben esa remuneración con sujeción a lo estipulado.

b. En el ámbito de las utilizaciones masivas, celebran contratos generales con asociaciones de usuarios de su repertorio y fijan tarifas generales por la utilización del mismo.

c. Permiten hacer efectivos los derechos de naturaleza compensatoria (por ejemplo, remuneración por copia privada).

d. Realizan el reparto de la recaudación neta correspondiente a los titulares de derechos.

e. Prestan servicios asistenciales y de promoción de los autores y artistas intérpretes o ejecutantes.

f. Asimismo, protegen y defienden los derechos de propiedad intelectual contra las infracciones que se cometan, acudiendo en su caso a la vía judicial (Ministerio de Cultura de España).

La Ley No. 312, "Ley de Derechos de Autor y Derechos Conexos" de nuestro país, determinó un marco jurídico de la gestión colectiva similar al que es utilizado en España. Su funcionamiento se basa en que los 
titulares de derechos de propiedad intelectual únicamente pueden lograr su real efectividad actuando colectivamente, a través de organizaciones que ejerzan las facultades de mediación o gestión de los derechos mencionados (Bendaña Guerrero, 2006).

La sociedad de gestión NICAUTOR, en su Estatuto de constitución ${ }^{17}$ se planteó como finalidad dedicarse a la gestión colectiva y administración por delegación de derechos de autor y derechos conexos, de carácter patrimonial, por cuenta y en interés de varios de sus titulares o concesionarios, en exclusiva.

Defender y proteger los derechos de autor través de la recaudación de la explotación de la creación musical por terceros, mediante las siguientes actividades:

- Defender los intereses morales y patrimoniales de sus asociados y causahabientes,

- Administrar el repertorio de las obras de sus asociados en el país y en el extranjero, por cualquier forma de explotación o utilización por medios conocidos.

- Celebrar pactos de defensa común y de representación administrativa con asociaciones similares en el país y en el extranjero.

- Vigilar el fiel cumplimiento de los convenios internacionales y normas legales que amparen el derecho de autor e instar la sanción de otras leyes, decretos o resoluciones que tiendan a respetar o perfeccionar su protección.

- Fijar las tarifas del repertorio administrado y conceder, reglamentar o denegar autorizaciones para la utilización del mismo, y suscribir los contratos pertinentes.

- Representar a sus socios y a los de instituciones extranjeras con las que tengan convenios para la defensa de sus derechos, en virtud de lo cual tendrá amplias facultades para asegurar el respeto del patrimonio que administra, percibir los aranceles generados, actuar ante las autoridades administrativas y judiciales mediante denuncias o querellas penales.

- Fomentar la mayor producción de realizaciones artísticas y la adopción de medidas de previsión social,

17 En La Gaceta, Diario Oficial No. 213 del 2 de noviembre de 2004, fue publicada la Escritura de Constitución y Constancia de Inscripción del Departamento de Registro y Control de Asociaciones del Ministerio de Gobernación de NICAUTOR. 
- Participar y establecer relaciones con asociaciones que tengan fines similares.

- Gestionar ante organismos y agencias internacionales recursos financieros para alcanzar los fines de la asociación.

- Facultar al representante legal de la asociación a aceptar donaciones, herencias, legados y realizar todos los actos necesarios para la consecución de los fines establecidos ${ }^{18}$.

\section{La remuneración y el reparto}

La experiencia ha demostrado que la falta de claridad en el proceso de distribución ocasiona considerables controversias entre los autores o los editores. El procedimiento de distribución debe describirse mediante normas precisas. La Junta de la sociedad aprobará las normas correspondientes antes de que se realicen los primeros pagos. Las cuestiones de distribución no se tratarán en la Asamblea General de autores y editores, puesto que se trata de cuestiones técnicas cuyo examen no conviene realizar en grandes reuniones donde hay intereses divergentes.

Por ello, se recomienda que la estructura de distribución se mantenga lo más sencilla posible, que las clases de distribución correspondan a los principales tipos de utilización de las obras: radio, televisión, restaurantes y hoteles, conciertos, salas cinematográficas, así como productoras discográficas. Otras clases de distribución dependerán de las características particulares de la vida cultural nacional.

En la medida de lo posible, todas las disposiciones sobre distribución deberían corresponder con el principio de "suum cuique" (a cada uno lo suyo), es decir que cada autor y editor debería recibir la cuantía equivalente al ingreso que la sociedad de derecho de autor ha obtenido para él (Uchtenhagen, 2005).

Cuando el autor administra individualmente sus derechos, su gestión comprende dos aspectos: negociar con el usuario las condiciones de la autorización y conferirla y efectuar la recaudación. La autorización es el medio por el cual se obtiene la licitud del uso y el autor la otorga a través

18 Escritura de Constitución de NICAUTOR, publicado en La Gaceta, Diario Oficial número 213, del 2 de noviembre de 2004. 
del contrato, en el que se estipulan las condiciones a las que se sujeta la explotación de la obra (Lipszyc, 1993).

En este contrato se regulan los derechos de carácter personal del autor - características y calidad de la edición, de la representación, etc.; forma, lugar, tamaño de las letras que se emplearán para la mención del nombre del autor, etc.-; los derechos de carácter patrimonial -plazos para efectuar la utilización, número de ejemplares o de difusiones, monto de la remuneración, forma, lugar, tiempo en que el autor efectuará la recaudación de los importes por el uso de su obra -; y las demás cuestiones propias de todo contrato como la causales de resolución y de conclusión.

Cuando es una organización de gestión colectiva la que realiza la administración de los derechos de autor, a las actividades de negociar condiciones con el usuario, convenir la remuneración, conferir la autorización, llevar a cabo la recaudación, se le agrega la de distribución o reparto de las sumas percibidas (Lipszyc, 1993).

Las sociedades que realizan gestión colectiva de derechos de ejecución pública, acuerdan las autorizaciones de uso sin previa consulta con los autores, esto es la administración colectiva plenamente desarrollada; y que el método primordial empleado para ello son las licencias generales o contratos de repertorio, por medio de los cuales estas sociedades autorizan a los difusores, en la forma, el lugar y durante el plazo convenidos en la licencia, el uso de todas las obras del repertorio que administran, generalmente llamado repertorio mundial de obras o repertorio mundial de música protegida (Lipszyc, 1993).

En los contratos tipo de representación recíproca entre sociedad de derechos de ejecución pública, se entiende que son todas las audiciones y ejecuciones efectuadas en público, en un lugar cualquiera dentro del territorio en que actúa cada una de las sociedades contratantes, por cualquier medio y de la manera que sea.

Entre las ejecuciones públicas están comprendidas las realizadas por medios humanos, instrumentales o vocales; por medios mecánicos tales como discos fonográficos, hilos, cintas y bandas sonoras; por los procedimientos de proyección, de difusión y transmisión tales como radiotransmisión, televisión, emisiones directas, repeticiones, 
retransmisiones, etc.; así como por los procedimientos de radiorecepción, dispositivos análogos y medios similares.

Las autorizaciones globales son una particularidad del sistema de gestión colectiva del derecho de ejecución pública y por medio de ellas, la sociedad de autores confiere al difusor la facultad de utilizar una o más obras del repertorio que administran y la amplitud del mismo depende de la cantidad de autores de obras nacionales que han confiado la administración de sus derechos, y del número de contratos de representación que ha logrado suscribir con sus homólogos de otros países (Lipszyc, 1993).

Las sociedades con importante trayectoria y prestigio representan prácticamente toda la música existente, que en conjunto se denomina repertorio mundial de música protegida. Los difusores pueden utilizarla según sus necesidades y en iguales condiciones, pues la administración colectiva de obras extranjeras tiene como premisa dispensar igualdad de trato respecto de las nacionales, en base al principio de trato nacional establecido en las Convenciones Internacionales sobre derecho de autor.

El monto de la remuneración -tarifa o arancel mínimo-, constituye uno de los puntos principales en las negociaciones entre la organización de la gestión colectiva y las entidades que representan a los difusores. Cuando no se logra llegar a acuerdos, en ciertos países se aplica un sistema de arbitraje o un sistema especial de mediación u otro procedimiento análogo (Lipszyc, 1993).

Las tarifas se convienen según la clase de utilización de que se trate y varían según los países; sin embargo, algunas reglas pueden considerarse tradicionales, por ejemplo, en materia de ejecución pública de obras musicales, del $10 \%$ al $15 \%$ en recitales y del $6 \%$ al $12 \%$ en general; del 10 al $15 \%$ en materia de representación teatral de obras dramáticas, dramático - musicales y coreográficas, etc (Lipszyc, 1993).

Algunas formas de remuneración convenidas por las sociedades de autores:

a) Remuneración proporcional o a porcentaje (Lipszyc, 1993)

- De los ingresos obtenidos por el difusor por venta de entradas (ejecución de obras musicales en salas de espectáculos y otros lugares públicos, por representación de obras dramáticas, dramático-musicales y coreográficas; por las recitaciones), 
- De los ingresos obtenidos por el difusor por venta de espacios publicitarios (por radiodifusión sonora de obras musicales),

- Por analogía sobre la recaudación potencial que debería haberse obtenido (por ejecución de obras musicales, representación de obras dramáticas, dramático-musicales y coreográficas en espectáculos con entrada libre),

- De los ingresos que potencialmente espera obtener el usuario en una comercialización posterior, por venta mensual de espacios publicitarios del canal de televisión (por difusión de obras musicales), venta de ejemplares (grabaciones fonográficas), venta de entradas al cinematógrafo (obras musicales incluidas en films), del precio de venta o alquiler de ejemplares (obras musicales incluidas en obras cinematográficas reproducidas en videocasetes) (P. 450).

b) Remuneración a tanto alzado (tarifa fija) (Lipszyc, 1993)

- Por derechos de sincronización,

- Por inclusión en filmes de libros cinematográficos originales y de adaptaciones,

- Por radiodifusión de libretos radiales y de televisión,

- Por radiodifusión de obras literarias y dramáticas y de adaptaciones de estas,

- Por teledifusión de obras cinematográficas respecto de los libros cinematográficos y de las adaptaciones al cine de obras literarias y dramáticas incluidas en los filmes,

- Por la proyección o exhibición de films respecto de los libros cinematográficos originales y de las adaptaciones,

- Por conferencias,

- Por ejecución de obras musicales en fiestas sociales de acuerdo a la importancia y categoría del local,

- Por utilización de obras musicales en líneas aéreas,

- En sustitución del porcentaje en algunos casos de recitación y representación teatral de obras dramáticas, dramáticomusicales y coreográficas con entrada libre. (P. 451).

Se practica también a tanto alzado cuando lo usual es la remuneración por porcentaje, pero falta la base de cálculo por ejemplo por la ejecución de obras musicales en radiodifusoras no comerciales. 
c) Remuneración mixta (Lipszyc, 1993, pág. 451)

- Por porcentaje con un mínimo fijo (ejecución de obras musicales en locales con o sin derecho a baile),

- Una suma fija y un porcentaje de los ingresos o ganancias del productor, incluyendo premios y otras recompensas a la producción (inclusión en films de libros cinematográficos originales o de adaptaciones) (P. 451).

Todo pago por utilización de obras, debe estar acompañado del programa de los actos de comunicación, indicar el lugar y la fecha en que se realizaron, los títulos de las obras difundidas, el nombre de sus autores y todas las otras constancias requeridas por la sociedad de autores y cuando la remuneración es a porcentaje, el difusor debe presentar una declaración de ingresos. Esa información es fundamental para que la organización de gestión colectiva pueda fiscalizar la corrección del pago y repartir las sumas globales recaudadas entre los autores de las obras difundidas (Lipszyc, 1993).

La gestión de derechos de autor necesita que las actividades de recaudación y vigilancia sean apoyadas por disposiciones legales y administrativas apropiadas y en caso de contienda entre las sociedades de autores y los utilizadores, sean dirimidos por encargados que atiendan adecuadamente las características del negocio jurídico de la difusión de obras y las dificultades inherentes a la administración de los derechos de autor.

La organización de gestión colectiva debe transformar una recaudación global en pagos individuales, para ello debe conocer efectivamente cuales fueron las obras utilizadas, los autores de la versión difundida y sus derechohabientes, cual es la proporción del arancel que corresponde a cada uno y cuáles son las organizaciones de gestión colectiva que los representan, a fin de efectuar el reparto (Lipszyc, 1993).

Las declaraciones del difusor constituyen el elemento primordial por medio del cual la sociedad de autores conoce las obras que se ejecutaron, para ello necesita documentación técnica, expresión con la que se hace referencia a todos los datos relativos a los autores, los editores y las obras. Estos datos están expresados de manera esquemática pero completa, se refieren tanto al repertorio propio de la sociedad como al que administra en virtud de los contratos de representación, que suscriben con sus homólogas extranjeras, estas según Lipszyc, (1993) son: 
- Las declaraciones de los autores, editores y subeditores;

- Un fichero de obras administradas por la entidad;

- La lista CAE (compositor - autor - editor), contiene más de 1,300.000 autores y 250.000 editores de todo el mundo con la indicación de estar o no afiliados a una sociedad de autores y la precisión de los territorios de gestión.

- La lista WWL (World Works List), lista de obras musicales no teatrales conocidas internacionalmente y utilizadas corrientemente, que las sociedades han escogido de su repertorio. En ellas se consigna el título y subtítulo de cada obra, los nombres de los autores y editores con su número CAE y la proporción que a cada uno le corresponde en el reparto de los derechos.

- Las fichas internacionales, medio tradicional de intercambio directo de documentación entre las sociedades. Constituyen un formulario estándar que llena cada sociedad respecto de las obras de las cuales son socios los derechohabientes y las remiten a aquellas con las que tiene contratos de representación.

- El cue-sheet, también llamado "programa musical" o "guión musical", es la documentación de obra audiovisual. Se trata de un formulario estándar de intercambio directo entre las sociedades, que se utiliza para distribuir lo recaudado para las obras musicales incluidas en obras audiovisuales.

- Los listados de investigación o de obras no identificadas (inquiry lists), son aquellas de las cuales no dispone su documentación en el momento del reparto, y aquellas a las que no puede aplicar la regla de Varsovia, según la cual, cuando una obra solo se identifique por el nombre del compositor, sociedad de una entidad, se debe enviar a esta sociedad la totalidad de los derechos.

- El fichero de acuerdos generales GAF (General Agreement File), constituye una recopilación de todos los contratos firmados entre editores de música que tienen por objeto catálogos de edición enteros, por mandato de la CISAC (pp. 454-455). 
Los sistemas básicos para efectuar la distribución de acuerdo con Lipszyc (1993) son:

a. De información completa, consiste en que los elementos de información reunidos para adjudicar los importes recaudados permiten individualizar cada utilización de la obra y asignar directamente a cada autor o derechohabiente la suma que le corresponde por ella. Se aplica sin dificultades con respecto a la utilización de obras dramáticas, dramático-musicales y coreográficas y en algunas utilizaciones de obras musicales no dramáticas, como espectáculos, conciertos, recitales, etc., música ejecutada "en vivo", radiodifusión, proyección o exhibición de films en salas cinematográficas y en todos los casos en que sea técnica y económicamente posible. Cuando en la información no se consignan las obras que realmente se ejecutaron, obliga a recurrir a la distribución indirecta por métodos de muestreo o sondeo, controlar a los difusores por medio de inspectores, realizar grabaciones, levantar actas notariales de comprobación, etc. También se aplican los sistemas de información de muestreo o de presunciones, en los casos que resulta imposible obtener los programas o el detalle de las obras difundidas, tal es el caso de ejecuciones por medios mecánicos o rocolas.

b. De información selectiva o de muestreo parte de la base de que la información recibida para distribuir no cubre la totalidad de lo recaudado, ya sea por falta de información de algunos usos comprobados, información no confiable, porque el importe que arrojan los programas no tienen relación con el costo del proceso de liquidación, de manera que se debe descontar a los autores una porción para cubrir los costos operativos. Los muestreos deben hacerse de forma que resulten veraces, representativos de todos los autores cuyas obras son difundidas y económicos en la relación costo-beneficio. Es recomendable utilizar el moderno sistema de muestreo estadístico-zonalestratificado, en los países donde las leyes obligan al intérprete y al usuario a llenar sus respectivas planillas de ejecución, debe exigirse su presentación, estableciendo inspecciones periódicas, secretas y sorpresivas, para constatar la veracidad de dichas planillas (pp. 456-457). 
Al ingresar las planillas a la sociedad, se procede a su clasificación zonal y estratificada, por zona, tipo de repertorio ejecutado y el importe de la recaudación. En la clasificación estadística y su selección no debe intervenir ningún funcionario de la sociedad, se realizará por sorteo o programación, pues de acuerdo con estas planillas elegidas estadísticamente y al azar dentro de cada grupo, se liquidarán la totalidad de los derechos recaudados. El muestreo debe tener las cualidades de ser tomado al azar, de forma estratificado y asimétrico.

$\mathrm{Al}$ azar para estar seguros que la muestra se asemeja al total que ella representa, estratificado porque los datos utilizados para cuantificar son imprecisos, y para lograr precisión se debe agrupar a los usuarios, las ejecuciones o el medio y así elaborar una muestra de cada uno de los estratos y asimétrico considerando que cada estación paga distintas cantidades, es mas válido determinar las ejecuciones en las estaciones que pagan mayor cantidad, porque es más grande el volumen del muestreo de las ejecuciones que lleva a cabo ese usuario.

c. De información sustitutiva o de presunciones (Lipszyc, 1993), consiste en concentrar el procesamiento de los datos en cierto tipo de información suficientemente completo, confiable y controlable, que desde el punto de vista estadístico pueda representar una aproximación a la realidad del repertorio utilizado por los usuarios.

d. De calificaciones (Lipszyc, 1993), consiste en valorar dentro del proceso de distribución, ciertas obras cuya duración es superior a la duración general promedio. Es usualmente utilizada respecto de las obras sinfónicas y de cámara. En el prorrateo de los derechos se asignan valores diferentes a las obras musicales según su género, por ejemplo: una ejecución, a tangos, sambas, valses, twists, etc.; dos ejecuciones, a preludios, nocturnos, rapsodias, serenatas, minuetos, suites, popurrís de más de cien compases, etc., cuatro ejecuciones a sonatas, oberturas, tríos, cuartetos, quintetos, sextetos, etc. y ocho ejecuciones, a sinfonías, misas, oratorios, grandes corales.

En cuanto a las reglas de reparto entre los autores y sus derechohabientes, cada sociedad de gestión colectiva establece las que más se adecuan a los usos y costumbres vigentes en el país respectivo y observando las decisiones adoptadas por las Asambleas Confederales de la CISAC.

Cuando se trata de obras musicales editadas, uno de los criterios de distribución aceptado es el que atribuye 1/3 para los compositores, $1 / 3$ para los autores de la letra y $1 / 3$ para el editor. Cuando interviene un arreglador musical o versionista, recibe un $25 \%$ de la parte de los compositores o de los autores de la letra respectivamente. 
La participación del editor en la recaudación por ejecución pública y por derechos fonomecánicos varía según las particularidades nacionales, ejemplo: en Argentina es el 25\% cuando se trata de obras no grabadas, $33.33 \%$ cuando tiene grabación; en Brasil es $25 \%$ en ambos casos, en Francia es $33.33 \%$ en ejecución pública y 50\% en fonomecánico, en Suiza es 35\% en ejecución pública y 50\% en fonomecánico. La parte del editor o del conjunto de las partes, sin importar el número de editores, o subdirectores de una obra, en ningún caso puede exceder el 50\% del total de la recaudación que corresponde a la obra. En el caso de obras inéditas, la distribución se efectúa entre compositores y autores de la letra por partes iguales, cualquiera que sea el número de ellos (Lipszyc, 1993).

La organización de gestión colectiva retiene una parte de la recaudación para solventar sus costos administrativos, se considera aceptable hasta el 30\% para la gestión de los derechos de ejecución pública y de radiodifusión y el 20\% en materia de derechos de reproducción mecánica y de representación (Lipszyc, 1993).

En la legislación nacional, la Ley No. 312, habilita a la Oficina Nacional de Derechos de Autor y Derechos Conexos, para ejercer funciones de vigilancia y control sobre las entidades de gestión. Para hacer posible la vigilancia faculta a la mencionada oficina, exigir de estas sociedades cualquier tipo de información, ordenar inspecciones y auditorías y designar un representante que asista con voz y sin voto a las reuniones de los órganos colectivos de la sociedad. Esta última atribución supone enviar un delegado para tal fin.

Respecto al nombramiento o cese de los administradores o apoderados, los aranceles que establezcan y los acuerdos que celebren sus asociaciones de usuarios, y los contratos de representación que suscriban con organizaciones extranjeras de su clase, se requiere que la sociedad de gestión los notifique al Registro de la Propiedad Intelectual, no a la Oficina Nacional de Derechos de Autor y Derechos Conexos ${ }^{19}$.

19 Art. 128 LDA: Corresponde a la Oficina Nacional de Derechos de Autor y Derechos Conexos, además de las facultades establecidas en este Capítulo, el control y vigilancia de sus actividades en lo que respecta al cumplimiento de las obligaciones y requisitos establecidos en este Capítulo.

A estos efectos la oficina podrá exigir de estas sociedades cualquier tipo de información, ordenar inspecciones y auditorías y designar un representante que asista con voz y sin voto a las reuniones de los órganos colectivos de la sociedad.

Con igual finalidad, las sociedades de gestión notificarán al Registro los nombramientos y ceses de sus administradores y apoderados generales, los aranceles que establezcan y los acuerdos que celebren con asociaciones de usuarios, y los contratos de representación que suscriban con organizaciones extranjeras de su clase.

Por lo que respecta a la aprobación de las modificaciones de estatutos, ésta se entenderá concedida por el Registro si no se notifica resolución en contrario en el plazo de tres meses desde su presentación. 
De acuerdo con Bendaña Guerrero (2006) el artículo 129 la Ley establece la creación en el Registro de la Propiedad Industrial e Intelectual, de la Oficina Nacional de Derechos de Autor y Derechos Conexos, la que tendrá las siguientes funciones:

1. Promover la creación intelectual nacional.

2. Estimular, fomentar y difundir el Derecho de Autor y los Derechos Conexos.

3. Fortalecer la protección a las manifestaciones culturales.

4. Tener a su cargo el Registro de Derechos de Autor y Derechos Conexos.

5. Actuar como árbitro en las controversias cuando así lo soliciten las partes involucradas.

6. Promover la cooperación internacional en la materia.

7. Velar y tener a su cargo el control de las sociedades de gestión colectiva (pág. 225).

En los artículos 130 y 131 LDA, se refiere al Registro para efectos de titularidad de los derechos de autor, así como los actos de transmisión entre vivos; los derechos por registro de inscripción de las obras, o producciones y las correspondientes a la cesión u otra formas de constitución de derechos y demás documentos a que se refiere, se establecerán en el Reglamento. Estas inscripciones son de carácter declarativo; sin embargo, la falta del registro o depósito no perjudica la adquisición y el ejercicio de los derechos establecidos en esta Ley. (Bendaña Guerrero, 2006)

\section{NICAUTOR, un ejemplo en nuestro medio}

La Sociedad de Gestión Colectiva de Derechos de Autor y Derechos Conexos de Nicaragua, NICAUTOR; fue fundada en abril del año 2003 por los autores y compositores más representativos en el arte musical nicaragüense.

NICAUTOR es una asociación civil sin fines de lucro, autorizada por la Asamblea Nacional mediante Decreto No. 3731 publicado en La Gaceta, Diario Oficial No. 26 del 6 de febrero del año 2004; se encuentra inscrita como persona jurídica, en el Departamento de Registro del Ministerio de Gobernación, bajo el No. 2843; folio: 567 al 576; Tomo I., Libro VIII. Sus Estatutos fueron publicados en La Gaceta Diario Oficial No. 213, del 2 de noviembre del año 2004 (NICAUTOR). 
Se fundó con el objetivo de gestionar y administrar los derechos autorales y patrimoniales sobre obras musicales de sus asociados y representados. NICAUTOR fue creada para hacer valer, proteger, recaudar y distribuir derechos en nombre de los autores nacionales y extranjeros, cuando existe uso y explotación en sus diversas modalidades de obras musicales protegidas.

Se encuentra registrada en el Registro de la Propiedad Intelectual de Nicaragua del Ministerio de Fomento, Industria y Comercio, bajo el número No. SG-01-2005. Sus aranceles generales fueron publicados en La Gaceta, Diario Oficial No. 223 del diecisiete de noviembre de 2005. En ellos se listan a todos los usuarios de obras musicales protegidas que deben de pagar.

Las instituciones del Estado que fungen como rectoras del quehacer de NICAUTOR son el Ministerio de Fomento, Industria y Comercio y el Ministerio de Gobernación, quienes ejercen la función de vigilantes y fiscalizadores; esa función también es ejercida por los mismos autores y la CISAC (Confederación Internacional de Sociedades de Autores y Compositores), en donde NICAUTOR es la Sociedad No. 212.

Si bien NICAUTOR se ocupa de la gestión de derechos patrimoniales de sus representados, se hace necesario crear las condiciones para el rescate, promoción y proyección de las obras musicales, de las distintas generaciones de autores de nuestro país, por ello se ha propuesto como un reto desarrollar un programa de promoción artística y apoyo a proyectos de sus asociados.

Por los contratos de adhesión, NICAUTOR representa 435 obras nacionales y por convenios internacionales, representa más de 4 millones de obras musicales extranjeras, mediante la suscripción de convenios internacionales con otras organizaciones de gestión colectiva.

En asamblea general se aprobaron pensiones vitalicias, para dos de los más célebres autores de nuestro país, Maestro Camilo Zapata y Maestro Jorge Isaac Carvallo (NICAUTOR, Memoria).

La organización y funcionamiento de NICAUTOR encuentra su fundamento legal en el artículo 113 de la Ley 312, donde se establece la figura de gestión colectiva en Nicaragua, para dedicarse en nombre 
propio o ajeno, a la gestión de Derecho de Autor o Derechos Conexos de carácter patrimonial, por cuenta y en interés de varios de sus titulares o concesionarios en exclusiva.

La facultad de NICAUTOR para emitir licencias musicales o contratos autorizantes por el uso y explotación de las obras musicales protegidas por la Ley, se encuentra en el artículo 121 de la Ley No. 312.

La distribución y recaudación a los legítimos propietarios delo recaudado, lo señala el artículo 122 de la Ley No. 312. Para el cumplimiento de esta disposición se usan Convenios, mandatos y acuerdos internacionales de representación y sistemas informáticos, que contienen el repertorio musical universal. La Sociedad de Gestión Colectiva o NICAUTOR, es miembro de la Confederación Internacional de Sociedades de Gestión Colectiva, quien sirve de órgano rector.

La potestad de NICAUTOR de establecer aranceles aplicables a todo uso y explotación de obras musicales protegidas, así como la autoridad para negociar dichos aranceles con las asociaciones de usuarios que sean representativas del sector correspondiente y que lo soliciten, se encuentra en el artículo 125 de la Ley No. 312.

Según el artículo 126 de la norma, las sociedades de gestión podrán solicitar de los usuarios, y éstos estarán obligados a facilitar, información para fijar y aplicar los aranceles, así como para realizar el reparto de las remuneraciones recaudadas. Las sociedades de gestión están obligadas a salvaguardar el secreto de los negocios de sus usuarios.

Los beneficios otorgados a los autores para ejercer su derecho de percibir beneficios económicos provenientes de la utilización de la obra por cualquier medio, forma o proceso, tal como lo establece el artículo 23 de la Ley; se encuentra establecido en el artículo 7 del Reglamento de la Ley de Derechos de Autor y Conexos. Igualmente, se concede a los artistas intérpretes o ejecutantes el derecho de percibir beneficios económicos provenientes de la utilización de interpretaciones o ejecuciones no fijadas por cualquier medio, forma o proceso.

El artículo 118 de la ley, le otorga fuerza ejecutiva a los documentos que emita la sociedad de gestión para realizar el cobro por la utilización de obras artísticas y/o musicales, literarias, científicas; efectuadas a 
personas naturales o jurídicas y únicamente se le pueden oponer las excepciones de pago y la no utilización de obras protegidas.

Asimismo, faculta a la entidad de gestión para solicitar a la autoridad judicial competente, la suspensión de la comunicación pública o presentación de obras artísticas y/o musicales protegidas conforme la Ley, mientras esté pendiente el pago de los aranceles correspondientes.

En materia penal ${ }^{20}$, el artículo 247 contempla que por el ejercicio no autorizado del derecho de autor y derechos conexos: será sancionado con noventa a ciento cincuenta días multa o prisión de seis meses a dos años e inhabilitación especial por el mismo período para ejercer cargo, profesión, oficio, industria o comercio relacionado con la conducta delictiva, quien contraviniendo la ley de la materia, y con el propósito de obtener un beneficio económico para sí o para un tercero, realice cualquiera de los actos siguientes sin autorización escrita del titular del derecho: La traducción, arreglo, u otra transformación de la obra; La comunicación pública de una obra o fonograma por cualquier forma, medio o procedimiento, íntegra o parcialmente. La retransmisión, por cualquier medio alámbrico o inalámbrico de una emisión de radiodifusión; (...)

NICAUTOR se ha planteado el ejercicio de sus funciones para cumplir con sus objetivos mediante las siguientes acciones:

1. NICAUTOR está obligada facilitarle a los usuarios de obras musicales protegidas, toda la información jurídica y técnica necesaria, a fin de satisfacer todas sus inquietudes, preguntas e interrogantes, sobre la existencia de la obligación de pago de derecho de autor y derechos conexos por estar regulado en leyes de la República.

2. Es importante que el usuario de obras musicales protegidas identifique su tipo de establecimiento comercial en la tabla de aranceles generales de NICAUTOR, para determinar el arancel de ley que está obligado a pagar.

3. NICAUTOR espera de los usuarios de obras musicales protegidas, el reconocimiento del derecho de autor debido a que la música es un suministro indispensable para los establecimientos comerciales

20 Documento presentado en el Seminario Funcionamiento y Organización de la Primera Sociedad de Gestión Colectiva de Derecho de Autor "NICAUTOR". Realizado con el apoyo de la Organización Mundial de la Propiedad Intelectual OMPI y la Confederación Internacional de Sociedades de Autores y Compositores CISAC. Managua 4 de marzo de 2005. 
donde se genera riqueza, lo cual se facilita mediante el intercambio de información entre el usuario de obras protegidas (bar, restaurante, discoteca, hoteles, radio, televisión, casinos, roconolas, etc.) y NICAUTOR.

4. NICAUTOR espera que el usuario adquiera de inmediato la Licencia Musical. En la medida que se clasifique el uso de la música, se establecerá el arancel a pagar.

5. Una vez firmada la Licencia Musical, NICAUTOR le extiende al usuario, Constancia de No Retención de la Dirección General de Ingresos y Alcaldía Municipal. Por recibido el primer pago, NICAUTOR extiende recibo oficial de caja.

6. Para reducir costos administrativos a ambas partes, los pagos por montos bajos se plantean recaudarlos como mínimo, semestral o anualmente.

7. NICAUTOR extiende Certificado de Licencia Musical para ser fijada en un lugar a la vista del público.

8. Existe seguimiento permanente a la Licencia Musical en la medida que se use la música.

El 12 de octubre del año 2005, la Sociedad de Gestión Colectiva NICAUTOR, comunicó al Registro de la Propiedad Intelectual, el establecimiento de los aranceles generales que determinan la remuneración por la utilización de obras en los diferentes tipos de establecimientos comerciales. Una vez autorizados dichos aranceles, éstos fueron publicados en La Gaceta Diario Oficial No. 223, el día 17 de noviembre del año 2005 .

Como indicador económico para la fijación de tarifas a los usuarios de música en Nicaragua se tomo el promedio del salario mínimo, mismo que consiste en la cantidad de un mil trescientos córdobas (CA \$ 1,300.00), los que son equivalentes a setenta y cinco pesos centroamericanos (CA $\$ 75.00)$. Es así que se fija la Unidad de Derecho de Autor (UDA), correspondiente a un día de salario mínimo, en la cantidad de dos pesos centroamericanos con 55/100 centavos (CA $\$ 2.55$ ), lo que equivale a dos dólares con cincuenta y cinco centavos de dólar (US\$2.55). Se estimó que fuera una unidad de medida práctica, eficaz, dinámica y de fácil aplicación, para que la comunicación entre la Sociedad de Autores y los Usuarios, sea de pleno entendimiento y confianza ${ }^{21}$.

21 Documento presentado en el Seminario Funcionamiento y Organización de la Primera Sociedad de Gestión Colectiva de Derecho de Autor "NICAUTOR". Realizado con el apoyo de la Organización Mundial de la Propiedad Intelectual OMPI y la Confederación Internacional de Sociedades de Autores y Compositores CISAC. Managua 4 de marzo de 2005. 
El monto a pagar en concepto de aranceles varía en dependencia de las características del negocio y del grado de importancia de la música para el establecimiento. Se tienen establecidas las siguientes categorías:

1. Música indispensable: Cuando la música es el principal generador de ingresos.

a) Ingreso único. Cuando la música general el ingreso total (Conciertos, Recitales etc.). El cobro es en porcentaje (\%)

b) Ingreso compartido. Cuando la música no genera el ingreso total y existen otros elementos de comercialización que se originan por la utilización de la música (Discoteca o Cabaret). El cobro es en porcentaje (\%) o unidad de medida por día de funcionamiento.

2. Música Necesaria: Cuando la música es parte importante en la generación de los ingresos (Bar con música viva, vídeo bar, etc.) El cobro es Unidad de medida por día de funcionamiento.

3. Música Accesoria: Cuando la música es un servicio adicional y no es representativa en la generación de ingresos (tiendas de autoservicio, hoteles, etc.) El cobro es Unidad de medida mensual (NICAUTOR, Aranceles).

En casos de contratos con empresarios de conciertos, recitales, bailes populares, etc., se incluye una cláusula especial, en donde los usuarios se obligan a proporcionar una lista que contenga el reporte de las obras utilizadas, así como el número de eventos a realizar. Lo anterior, con el objeto de que la sociedad tenga a su alcance los elementos necesarios para llevar a cabo las liquidaciones que a cada uno de sus representados corresponda.

Se incluye en los contratos con el usuario una cláusula de arbitraje, en la cual se indica y queda asentado que ambas partes reconocen como árbitro para cualquier controversia. En este caso se recomienda, a la autoridad de derechos de autor.

Estos instrumentos legales, además de fortalecer la credibilidad de las sociedades de gestión, proporcionan seguridad jurídica a los usuarios, ya que a través de las licencias de uso, se evita la incongruencia de que usuarios similares paguen diferente. 
Los elementos básicos utilizados por NICAUTOR para el establecimiento de tarifas son los siguientes:

- Características del usuario

- Las formas de uso:

* Música grabada

* Música en vivo

- Tipos de explotación:

* Lucro indirecto

* Lucro directo

- Costos de contratación y cobro

* Volumen de usuarios

* Extensión territorial

Últimamente, el presidente y director de la Asociación Sociedad de Gestión Colectiva de Derecho de Autor y Derechos Conexos de Nicaragua, Jorge Isaac Carballo y Engels Ortega, respectivamente, dijeron que NICAUTOR está actuando dentro del marco de las leyes establecidas en materia de protección de los derechos de autor, y lo que se cobra es un arancel aprobado por el Ministerio de Fomento Industria y Comercio, que está vigente desde el 17 de noviembre de 2005, sobre el uso y explotación de obras musicales.

Rechazaron argumentos de algunos dueños de restaurantes que se oponen al cobro, y confirmaron que la aplicación del arancel, - resultado de una homogenización de leyes y tratados internacionales en los que está adscrita Nicaragua-, se está llevando a cabo en una buena cantidad de negocios que utilizan música desde hace un poco más de dos años, el director de NICAUTOR aclaró que "nadie está obligado a utilizar música en su negocio, y los discos y videos están concebidos a venderse en las tiendas y por eso ambos productos traen una coletilla que dice para uso doméstico" (NICAUTOR, Memoria).

Mensualmente, NICAUTOR recauda el equivalente de cinco mil dólares, de los cuales el 60\% se envía a otras organizaciones similares que protegen en el exterior la explotación de las obras musicales, y un 40\% se utiliza para mantener la oficina e incluso hasta para el pago de tres pensiones vitalicias a compositores, que salen de un fondo social que tiene la organización, dijo el titular de la organización, el también compositor Jorge Isaac Carballo.

Carballo manifestó que un 40\% de los locales comerciales del país están cubiertos, "algo que no ha sido fácil, pero sí hay un reconocimiento de que el uso de las obras musicales aporta a los negocios y hay una concepción más clara que las obras musicales son privadas”. 
Confirmó el director de NICAUTOR que los supermercados están pagando el arancel hace un año, dependiendo del tamaño. El cobro es de 312 córdobas al mes. Sobre el caso de la música en las radios y estaciones televisivas, Ortega dijo que esto se les planteó, y "mientras estábamos negociando la radio y la televisión fueron a presentar un amparo administrativo contra los aranceles, y de ahí para acá no ha habido ninguna comunicación con nosotros". El amparo contra los aranceles se cayó, por lo que el tribunal de apelaciones falló que el cobro de los aranceles es legal y está vigente.

Actualmente, se encuentra radicado el recurso de amparo en mención en la Sala de lo Constitucional de la Corte Suprema de Justicia, pendiente de resolverse el fondo del asunto, en cuanto a los aranceles publicados por NICAUTOR (El Nuevo Diario, 2009).

\section{Conclusiones}

1. Los derechos de autor, que abarcan tanto los derechos morales como los derechos patrimoniales, se encuentran ampliamente protegidos en la legislación, particularmente sus derechos exclusivos de recibir beneficios económicos por todas las formas de utilización que se haga de sus obras; no obstante, la posibilidad de obtención de dichos beneficios, ha sido una aspiración ideal hasta la fecha, debido a que en nuestro país han sido muy pocos los autores que han utilizado la herramienta denominada "sociedad de gestión" como entidad encargada de velar por sus derechos, es decir que no han tenido por sí solos capacidad de realizar la función de recaudo por el uso de su obras artísticas y gozar de los frutos de su producción intelectual.

2. La actividad de las sociedades de gestión, se reconduce a la labor de representación de los titulares del derecho de autor, y por ello jurídicamente se entiende que sustituyen de forma legítima ante los terceros al titular, haciendo que se vincule el ámbito de poder y de responsabilidad del tercero con el del titular de los derechos a través de su gestión.

3. Si bien la sociedad de gestión NICAUTOR está constituida como una asociación sin fines de lucro, la labor de recaudación de los aranceles por utilización de las obras protegidas por los derechos de autor, es una tarea compleja, que de no organizar correctamente sus actividades y con la transparencia debida, podría dar lugar a cometer prácticas abusivas con la obtención de lucro indebido, en perjuicio de los autores. 
4. Dado que la Ley 312 concede a las sociedades de gestión la posibilidad de aceptar la administración de los derechos de autores extranjeros que le sean encomendados, existe el riesgo latente de que se dedique el mayor esfuerzo por recaudar el importe económico, conforme los aranceles establecidos, destinado a los autores extranjeros, y se descuide la vigilancia sobre la utilización de las obras nacionales, y por consiguiente en desmedro de los beneficios que éstos deberían percibir.

5. La sociedad de gestión ha enfrentado problemas, por la resistencia que oponen tanto los autores de obras artísticas, como los usuarios de las mismas, para realizar el pago de los aranceles de acuerdo con la normativa publicada por NICAUTOR y autorizada por el Ministerio de Fomento, Industria y Comercio. Sin embargo, se comprueba que la misma sociedad de gestión, no ha realizado suficientes esfuerzos con los principales sectores de usuarios, para exponerles de manera clara sus fines y objetivos y tratar de despejar las dudas sobre un posible enriquecimiento injusto amparados en una irreal protección de los derechos de los autores nacionales y extranjeros.

6. Desde la academia hay importantes trabajos realizados sobre este tema, y algunos de los cuales han sido publicados ampliamente; sin embargo, es preciso continuar profundizando en su estudio, a la luz de la doctrina, la jurisprudencia extranjera y los instrumentos internacionales, donde se recogen experiencias similares a las que actualmente está enfrentando actualmente NICAUTOR, como contribución al desarrollo de la cultura y el fomento del arte, bajo la premisa de velar siempre por la protección de los derechos de los autores.

\section{Recomendaciones}

1. Es importante fortalecer la figura de la sociedad de gestión NICAUTOR, única existente en Nicaragua, a partir del conocimiento de sus actividades e informes de gestión presentados a los autores que representan, para de esta manera generar mayor confianza en su labor y lograr una efectiva protección a los derechos de los autores e intérpretes.

2. Las instituciones del Estado encargadas por la ley para la labor de control y vigilancia, deben rendir informe sobre el seguimiento que se brinda a la entidad de gestión NICAUTOR, también publicar los reportes que la entidad de gestión presenta ante dichas oficinas 
sobre la recaudación que realizan en períodos concretos tiempo y el reparto a los autores cuyos derechos gestionan.

3. NICAUTOR, como sociedad de gestión colectiva que representa intereses de autores nacionales, a la vez que gestiona el recaudo de los aranceles por utilización de las obras de autores extranjeros, debe también incentivar la utilización de la obra de artistas nacionales y demostrar su preocupación por proteger sus derechos con carácter de prioridad.

4. Dado que en nuestra sociedad no se incentiva la creación de obras del intelecto, y se ha incrementado la "piratería" de producciones musicales, videos, etc., es preciso conocer más a fondo el problema, las implicancias económicas que tiene y poder informar y educar a la sociedad, encaminados a estimular la protección a los autores y que obtengan los beneficios económicos apropiados, de acuerdo con el resultado de su trabajo.

\section{Lista de referencias}

\section{Textos}

Arce Gargollo, J. Contratos mercantiles atípicos. Cuarta Edición, Editorial Porrua, 2004.

Antequera Parilli, R. Derecho de Autor. Tomo I y II. Editorial Venezolana C.A., 2da. Edición revisada y actualizada, 1998.

Bendaña Guerrero, G. J. Curso de Derecho de Autor y Derechos Conexos. $1^{\text {a }}$. Edición, PAVSA, Managua, 2006.

Bendaña Guerrero, G. J. Estudio de las nuevas leyes de Propiedad Industrial. 1 $^{\text {a }}$ Edición, PAVSA, Managua, 2003.

Cuadra Zavala, J. Anotaciones al Código Civil de la República de Nicaragua. Tomo I. 1 ${ }^{\text {a }}$. Edición. Editorial HISPAMER, Managua, Nicaragua. 2004.

De Castro y Bravo, F. La persona jurídica. $2^{\text {a }}$. Edición. Editorial Civitas, S.A. Madrid, 1984.

Diccionario Jurídico Mexicano. Instituto de Investigaciones Jurídicas. UNAM. Décima segunda edición. Editorial Porrúa. México, 1998. 
Diez-Picazo, L. y Gullón, A. Sistema de Derecho Civil. Vol. I. 10a. Edición. Editorial Tecnos. Madrid, 2002.

Guzmán García, J. J. \& Herrera Espinoza, J. J. Contratos Civiles y Mercantiles. Colección Facultad de Ciencias Jurídicas. Universidad Centroamericana. Impresiones Helios, S.A., Managua, Nicaragua, mayo de 2006.

Lipszyc, D. Derecho de autor y derechos conexos. Ediciones UNESCO, CERLALC, ZAVALIA. 1993.

Régimen Común sobre Derecho de Autor y Derechos Conexos. Decisión 351. Acuerdo de Cartagena. Derechos Intelectuales No. 7 (1996). Editorial Astrea. Buenos Aires.

\section{Legislación}

Constitución Política de la República de Nicaragua.

Ley No. 312. Ley de Derecho de Autor y Derechos Conexos. 26 de agosto de 1999. Publicado en La Gaceta, Diario Oficial No. 166 y 167 de31 de agosto y 1 de septiembre de 1999.

Ley No. 577. Ley de Reformas y Adiciones a la Ley No. 312, Ley de Derecho de Autor y Derechos Conexos. 22 de marzo del 2006. Publicado en La Gaceta, Diario Oficial No.6o del 24 de marzo del 2006.

Decreto No. 22-200o. Reglamento de la Ley de Derechos de Autor y Conexos. 3 de marzo del 2000. Publicado en La Gaceta, Diario Oficial No. 84 del viernes 5 de mayo del 2000.

Decreto No. 24-2006. Reformas al Decreto No. 22-200o, Reglamento de la Ley de Derechos de Autor y Conexos. 29 de marzo del 2006. Publicado en La Gaceta Diario Oficial No. 63 del 29 de marzo del 2006.

Ley No. 147. Ley General sobre Personas Jurídicas sin Fines de Lucro. 19 de marzo de 1992, publicada en La Gaceta Diario Oficial No. 102 del 29 de mayo de 1992. 
Declaración Universal de Derechos Humanos. Publicado por el Departamento de Información Pública de las Naciones Unidas. Reimpresión DPI/876 Rev.1 - 93604 - Agosto, 1993, pág. 15.

Convenio de Berna para la Protección de las Obras Literarias y Artísticas, del 9 de septiembre de 1886, y posteriores revisiones. Artículo 2.

\section{Consulta en línea}

Decreto Legislativo 1/1996, de 12 de abril. Recuperado el 13-10-2009 de http://www.mcu.es/propiedadInt/CE/GestionColectiva/ GestionColectiva.html

KOSKINEN-OLSSON, T. Del artista al público. El derecho de autor y los derechos conexos y el sistema de gestión colectiva del derecho de autor al servicio de los creadores y los consumidores Publicación de la OMPI N ${ }^{\circ}$ 922(S) Encontrado el 2 de diciembre de 2009 de: http://www.wipo.int/freepublications/es/copyright/922/wipo_ pub_922.pdf

Las entidades de gestión colectiva. Artículo publicado por el Ministerio de Cultura de España. Recuperado el 13 de octubre de 2009 de http:// www.mcu.es/propiedadInt/CE/GestionColectiva/Entidades.html

Ley de Derecho de Autor. Ley 44 de 1993. Colombia. Recuperado el 13 de octubre de 2009 de http://www.secretariasenado.gov.co/leyes/ LoO44_93.HTM.

Texto Refundido de la Ley de Propiedad Intelectual. Título IV del Libro III del Real

UCHTENHAGEN, Ulrich. El establecimiento de una sociedad de derecho de autor. Experiencias y observaciones. OMPI. Mayo, 2005. Recuperado el 20-10-2009 de: www.wipo.int/freepublications/es/ copyright/926/wipo_pub_926.pdf

VARGAS FERNÁNDEZ, N. Derecho de autor. Recuperado el 28-11-2009 de: http://www.tuobra.unam.mx/publicadas/o40219212417.html

ZAPATA LÓPEZ, F. La Gestión Colectiva del Derecho de Autor y los Derechos Conexos. Recuperado el 20 de octubre del año 2009 de: www.sieca.org.gt/cache/17990000000871.pdf 